\title{
Citizen science flow - an assessment of simple streamflow measurement methods
}

\author{
Jeffrey C. Davids ${ }^{1,2}$, Martine M. Rutten ${ }^{3}$, Anusha Pandey ${ }^{4}$, Nischal Devkota $^{4}$, Wessel David van Oyen ${ }^{3}$, \\ Rajaram Prajapati $^{4}$, and Nick van de Giesen ${ }^{1}$ \\ ${ }^{1}$ Water Management, Civil Engineering and Geosciences, Delft University of Technology, Building 23, \\ Stevinweg 1, $2628 \mathrm{CN}$, Delft, the Netherlands \\ ${ }^{2}$ SmartPhones4Water, 3881 Benatar Way, Suite G, Chico, California 95928, USA \\ ${ }^{3}$ Engineering and Applied Sciences, Rotterdam University, G.J. de Jonghweg 4-6, 3015 GG, Rotterdam, the Netherlands \\ ${ }^{4}$ SmartPhones4Water-Nepal, Damodar Marg, Thusikhel, 44600, Lalitpur, Nepal
}

Correspondence: Jeffrey C. Davids (j.c.davids@tudelft.nl)

Received: 7 August 2018 - Discussion started: 21 August 2018

Revised: 19 January 2019 - Accepted: 7 February 2019 - Published: 20 February 2019

\begin{abstract}
Wise management of water resources requires data. Nevertheless, the amount of streamflow data being collected globally continues to decline. Generating hydrologic data together with citizen scientists can help fill this growing hydrological data gap. Our aim herein was to (1) perform an initial evaluation of three simple streamflow measurement methods (i.e., float, salt dilution, and Bernoulli runup), (2) evaluate the same three methods with citizen scientists, and (3) apply the preferred method at more sites with more people. For computing errors, we used midsection measurements from an acoustic Doppler velocimeter as reference flows. First, we (authors) performed 20 evaluation measurements in headwater catchments of the Kathmandu Valley, Nepal. Reference flows ranged from 6.4 to $240 \mathrm{~L} \mathrm{~s}^{-1}$. Absolute errors averaged $23 \%, 15 \%$, and $37 \%$ with average biases of $8 \%, 6 \%$, and $26 \%$ for float, salt dilution, and Bernoulli methods, respectively. Second, we evaluated the same three methods at 15 sites in two watersheds within the Kathmandu Valley with 10 groups of citizen scientists (three to four members each) and one "expert" group (authors). At each site, each group performed three simple methods; experts also performed SonTek FlowTracker midsection reference measurements (ranging from 4.2 to $896 \mathrm{~L} \mathrm{~s}^{-1}$ ). For float, salt dilution, and Bernoulli methods, absolute errors averaged $41 \%, 21 \%$, and $43 \%$ for experts and $63 \%$, $28 \%$, and $131 \%$ for citizen scientists, while biases averaged $41 \%, 19 \%$, and $40 \%$ for experts and $52 \%, 7 \%$, and $127 \%$ for citizen scientists, respectively. Based on these re-
\end{abstract}

sults, we selected salt dilution as the preferred method. Finally, we performed larger-scale pilot testing in week-long pre- and post-monsoon Citizen Science Flow campaigns involving 25 and 37 citizen scientists, respectively. Observed flows ( $n=131$ pre-monsoon; $n=133$ post-monsoon) were distributed among the 10 headwater catchments of the Kathmandu Valley and ranged from 0.4 to $425 \mathrm{~L} \mathrm{~s}^{-1}$ and from 1.1 to $1804 \mathrm{~L} \mathrm{~s}^{-1}$ in pre- and post-monsoon, respectively. Future work should further evaluate uncertainties of citizen science salt dilution measurements, the feasibility of their application to larger regions, and the information content of additional streamflow data.

\section{Introduction}

\subsection{Background}

The importance of measuring streamflow is underpinned by the reality that it is the only truly integrated representation of the entire catchment that we can plainly observe (McCulloch, 1996). Traditional streamflow measurement approaches relying on sophisticated sensors (e.g., pressure transducers and acoustic Doppler devices), site improvements (e.g., installation of weirs or stable cross sections), and discharge measurements performed by specialists are often necessary at key observation points. However, these approaches require significant funding, equipment, and expertise and are often difficult to maintain, and even more so to scale (Davids et al., 
2017). Consequently, despite growing demand, the amount of streamflow data being collected continues to decline in several parts of the world, especially in Africa, Latin America, Asia, and even North America (Hannah et al., 2011; Van de Giesen et al., 2014; Feki et al., 2017; Tauro et al., 2018). Specifically, there is an acute shortage of streamflow data in headwater catchments (Kirchner, 2006) and developing regions (Mulligan, 2013). This data gap is perpetuated by a lack of understanding among policy makers and citizens alike regarding the importance of streamflow data, which leads to persistent funding challenges (Kundzewicz, 1997; Pearson, 1998). This is further compounded by the reality that the hydrological sciences research community has focused much of its efforts in recent decades on advancing modeling techniques, while innovation in methods for generating the data these models depend on has been relegated to a lower priority (Mishra and Coulibaly, 2009; Burt and McDonnell, 2015), even though these data form the foundation of hydrology (Tetzlaff et al., 2017).

Considering these challenges, alternative methods for generating streamflow and other hydrological data are being explored (Tauro et al., 2018). For example, developments in using remote sensing to estimate streamflow are being made (Tourian et al., 2013; Durand et al., 2014), but applications in small headwater streams are expected to remain problematic (Tauro et al., 2018). Utilizing cameras for measuring streamflow is also a growing field of research (Muste et al., 2008; Le Coz et al., 2010; Dramais et al., 2011; Le Boursicaud et al., 2016), but it is doubtful that these methods will be broadly applied in headwater catchments in developing regions soon because of high costs, a lack of technical capacity, and the potential for vandalism. In these cases, however, involving citizen scientists to generate hydrologic data can potentially help fill the growing global hydrological data gap (Fienen and Lowry, 2012; Buytaert et al., 2014; Sanz et al., 2014; Davids et al., 2017; van Meerveld et al., 2017; Assumpção et al., 2018).

Kruger and Shannon (2000) define citizen science as the process of involving citizens in the scientific process as researchers. Citizen science often uses mobile technology (e.g., smartphones) to obtain georeferenced digital data at many sites, in a manner that has the potential to be easily scaled (O'Grady et al., 2016). Turner and Richter (2011) partnered with citizen scientists to map the presence or absence of flow in ephemeral streams. Fienen and Lowry (2012) showed that water level measurements from fixed staff gauges reported by passing citizens via a text message system can have acceptable errors. Mazzoleni et al. (2017) showed that flood predictions can be improved by assimilating citizen science water level observations into hydrological models. Le Coz et al. (2016) used citizen scientist photographs to improve the understanding and modeling of flood hazards. Davids et al. (2017) showed that lower frequency observations of water level and discharge like those produced by citizen scientists can provide meaningful hydrologic information. Van
Meerveld et al. (2017) showed that citizen science observations of stream level class can be informative for deriving model-based streamflow time series of ungauged basins.

While the previously referenced studies focus mainly on involving citizen scientists for observing stream levels, we were primarily concerned with the possibility of enabling citizen scientists to take direct measurements of streamflow. Using keyword searches with combinations of "citizen science", "citizen hydrology", "community monitoring", "streamflow monitoring", "streamflow measurements", "smartphone streamflow measurement", and "discharge measurements", we found that research on using smartphone video processing methods for streamflow measurement has been ongoing for nearly 5 years (Lüthi et al., 2014; Peña-Haro et al., 2018). Despite the promising nature of these technologies, we could not find any specific studies evaluating the strengths and weaknesses of citizen scientists applying these technologies directly in the field themselves.

Etter et al. (2018) evaluated the error structure of simple "stick method" streamflow estimates (similar to what we later refer to as the float method) from 136 participants from four streams in Switzerland. Participants estimated crosssectional area with visual estimates of stream width and depth. Floating sticks were used to measure surface velocity, which was scaled by 0.8 to estimate average velocity. Besides this study, we could not find other evaluations of simple streamflow measurement techniques that citizen scientists could possibly use. Therefore, in addition to the stick method, we turned to the vast body of general knowledge about observing streamflow to develop a list of potential simple citizen science streamflow measurement methods to evaluate further (see Sect. 2.1 for details).

\subsection{Research questions}

Our aims in this paper were to (1) perform an initial evaluation of selected potential simple streamflow measurement methods, (2) evaluate these potential methods with actual citizen scientists, and (3) apply the preferred method at a larger scale. Our research questions are listed as follows.

- Which simple streamflow measurement method provides the most accurate results when performed by "experts"?

- Which simple streamflow measurement method provides the most accurate results when performed by citizen scientists?

- What are citizen scientists' perceptions of the required training, cost, accuracy, etc. of the evaluated simple streamflow measurement methods?

- Can citizen scientists apply the selected streamflow measurement method at a larger scale? 


\subsection{Context and limitations}

This research was performed in the context of a larger citizen science project called SmartPhones4Water or S4W (Davids et al., 2017, 2018; https://www.smartphones4water.org/, 15 July 2018). S4W leverages young researchers, citizen science, and mobile technology to improve lives by strengthening our understanding and management of water. S4W focuses on developing simple field data collection methods and low-cost sensors that young researchers and citizen scientists can use to fill data gaps in data-scarce regions. Our aim is to partner with young researchers, local schools, and communities to use these openly available data to improve the quality and applicability of their water-related research. S4W's first pilot project, S4W-Nepal, initially concentrated on the Kathmandu Valley and is now expanding into other regions of the country. S4W-Nepal facilitates ongoing monitoring of precipitation, stream and groundwater levels and quality, freshwater biodiversity, and several short-term measurement campaigns focused on monsoon precipitation, land use changes, stone spout (Nepali: dhunge dhara) flow and quality, and now streamflow. One immediate application in the Kathmandu Valley is to improve estimates of water balance fluxes, including net groundwater pumping.

While identifying and refining methods for citizen scientists to measure streamflow may be an important step towards generating more streamflow data, these types of citizen science applications are not without challenges of their own. For example, citizen science often struggles with the perception (and possible reality) of poor data quality (Dickinson et al., 2010) and the intermittent nature of data collection (Lukyanenko et al., 2016). Additionally, there are other non-citizenscience-based streamflow measurement methods (e.g., permanently installed cameras) that may undergo rapid development and transfer of technology and thus make a significant contribution towards closing the streamflow data gap.

Additionally, the use of "citizen scientist" herein is restricted to only student citizen scientists, which are a narrow but important subset of potential citizen scientists. Our vision was to partner with student citizen scientists first to develop and evaluate streamflow measurement methodologies. Once methodologies are refined in coordination with students, we aim to partner with community members and students in the rural hills of Nepal to improve the availability of quantitative streamflow and spring flow data.

\section{Materials and methods}

\subsection{Simple streamflow measurement methods considered}

Streamflow measurement techniques suggested in the United States Bureau of Reclamation Water Measurement Manual (USBR, 2001) that seemed potentially applicable for citizen scientists included deflection velocity meters, the ManningStrickler slope area method, and pitot tubes for measuring velocity heads. The float, current meter, and salt dilution methods described by several authors also seemed applicable (British Standards Institute, 1964; Day, 1976; Rantz, 1982; Fleming and Henkel, 2001; Escurra, 2004; Moore, 2004a, b, 2005; Herschy, 2009). Finally, Church and Kellerhals (1970) introduced the velocity head rod, or what we later refer to as the Bernoulli run-up (or just Bernoulli) method. Table 1 provides a summary of these eight simple measurement methods. For the categories of (1) inapplicability in Nepal (specifically to headwater catchments), (2) cost, (3) required training, and (4) complexity of the measurement procedure, a rank of either 1,2, or 3 was given by the authors, with 1 being most favorable and 3 being least favorable. Theses ranks were then summed, and the three methods with the lowest ranks (i.e., Bernoulli; float; and salt dilution, or slug) were selected for additional evaluation in the field.

\subsection{Expanded description of selected simple streamflow measurement methods}

\subsubsection{Float method}

The float method is based on the velocity-area principle, whereby the channel cross section is defined by measuring depth and width of $n$ subsections, and the velocity is found by the time it takes a floating object to travel a known distance which is then corrected for friction losses. In some cases, a single float near the middle of the channel (often repeated to obtain an average value) is used to determine surface velocity (Harrelson et al., 1994). In this study, surface velocity was measured at each of the $n$ subsections. Total streamflow $(Q)$ in liters per second $\left(\mathrm{L} \mathrm{s}^{-1}\right)$ is calculated with Eq. (1):

$Q=1000 \cdot \sum_{i=1}^{n} C \cdot V_{F_{i}} \cdot d_{i} \cdot w_{i}$,

where 1000 is a conversion factor from $\mathrm{m}^{3} \mathrm{~s}^{-1}$ to $\mathrm{L} \mathrm{s}^{-1}, \mathrm{C}$ is a unitless coefficient to account for the fact that surface velocity is typically higher than average velocity (typically in the range of 0.66 to 0.80 depending on depth; USBR, 2001) due to friction from the channel bed and banks, $V_{F_{i}}$ is the surface velocity from float in meters per second $\left(\mathrm{m} \mathrm{s}^{-1}\right), d_{i}$ is the depth (m), and $w_{i}$ is the width (m) of each subsection ( $i=1$ to $n$, where $n$ is the number of stations). A coefficient of 0.8 was used for all float method measurements in this study. Surface velocity for each subsection was determined by measuring the amount of time it takes for a floating object to move a certain distance. For floats we used sticks found on site. Sticks are widely available (i.e., easiest for citizen scientists), generally float (except for the densest varieties of wood), and depending on their density are between $40 \%$ and $80 \%$ submerged, which minimizes wind effects. An additional challenge with floats is that they can get stuck in eddies, pools, or overhanging vegetation. 
Table 1. Summary of simple streamflow measurement methods considered for further evaluation. Integer ranks of 1, 2, or 3 for inapplicability in Nepal (especially for smaller headwater catchments); cost; required training; and complexity were given to each method, with 1 being most favorable and 3 being least favorable. The three methods with the lowest rank were selected for further evaluation. Smartphones are not included in equipment needs because it was assumed that citizen scientists would provide these themselves. EC: electrical conductivity.

\begin{tabular}{|c|c|c|c|c|c|c|c|c|c|}
\hline No. & Method & Brief description & Equipment needs & $\begin{array}{r}\text { Inapplicability } \\
\text { in Nepal }\end{array}$ & Cost & $\begin{array}{r}\text { Required } \\
\text { training }\end{array}$ & Complexity & $\begin{array}{r}\text { Total rank } \\
\text { (4 to } 12)\end{array}$ & $\begin{array}{l}\text { Selected for } \\
\text { evaluation } \\
\text { (yes/no) }\end{array}$ \\
\hline 1 & Bernoulli & $\begin{array}{l}\text { Velocity-area method. Thin } \\
\text { flat plate (e.g., measuring } \\
\text { scale) used to measure veloc- } \\
\text { ity head. Repeated at multiple } \\
\text { stations. }\end{array}$ & Measuring scale & 1 & 1 & 2 & 1 & 5 & yes \\
\hline 2 & Current meter & $\begin{array}{l}\text { Velocity-area method. Current } \\
\text { meter (e.g., bucket wheel, pro- } \\
\text { peller, acoustic) used to } \\
\text { measure velocity. Repeated at } \\
\text { multiple stations. }\end{array}$ & $\begin{array}{l}\text { Current meter, } \\
\text { measuring scale }\end{array}$ & 2 & 3 & 3 & 2 & 10 & no \\
\hline 3 & Deflection rod & $\begin{array}{l}\text { Velocity-area method. Shaped } \\
\text { vanes projecting into the flow } \\
\text { along with a method to mea- } \\
\text { sure deflection and thereby } \\
\text { computing velocity. Repeated } \\
\text { at multiple stations. }\end{array}$ & $\begin{array}{l}\text { Deflection rod, } \\
\text { measuring scale }\end{array}$ & 3 & 2 & 2 & 2 & 9 & no \\
\hline 4 & Float & $\begin{array}{l}\text { Velocity-area method. Time } \\
\text { for floating object to travel } \\
\text { known distance used to deter- } \\
\text { mine water velocity at } \\
\text { multiple stations. }\end{array}$ & $\begin{array}{l}\text { Measuring scale, } \\
\text { timer }\end{array}$ & 2 & 1 & 2 & 1 & 6 & yes \\
\hline 5 & $\begin{array}{l}\text { Manning- } \\
\text { Strickler }\end{array}$ & $\begin{array}{l}\text { Slope area method. Slope of } \\
\text { the water surface elevation } \\
\text { combined with estimates of } \\
\text { channel roughness and chan- } \\
\text { nel geometry to determine } \\
\text { flow using the Manning- } \\
\text { Strickler equation. }\end{array}$ & $\begin{array}{l}\text { Auto level (or } \\
\text { water level), } \\
\text { measuring scale }\end{array}$ & 2 & 2 & 2 & 3 & 9 & no \\
\hline 6 & Pitot tube & $\begin{array}{l}\text { Velocity-area method. Pitot } \\
\text { tube used to measure velocity. } \\
\text { Repeated at multiple stations. }\end{array}$ & $\begin{array}{l}\text { Pitot tube, } \\
\text { measuring scale }\end{array}$ & 2 & 2 & 2 & 2 & 8 & no \\
\hline 7 & $\begin{array}{l}\text { Salt dilution } \\
\text { (constant-rate } \\
\text { injection) }\end{array}$ & $\begin{array}{l}\text { Constant rate of known con- } \\
\text { centration of salt injected } \\
\text { into stream. Background } \\
\text { and steady-state electrical } \\
\text { conductivity values measured } \\
\text { after full mixing. Flow is } \\
\text { proportional to rate of salt } \\
\text { injection and change in EC. }\end{array}$ & $\begin{array}{l}\text { EC meter, mixing } \\
\text { containers }\end{array}$ & 1 & 2 & 3 & 3 & 9 & no \\
\hline 8 & $\begin{array}{l}\text { Salt dilution } \\
\text { (slug) }\end{array}$ & $\begin{array}{l}\text { Known volume and concentra- } \\
\text { tion of salt injected as a } \\
\text { single slug. EC of break- } \\
\text { through curve measured. Flow } \\
\text { is proportional to integration } \\
\text { of breakthrough curve and vol- } \\
\text { ume of tracer introduced. }\end{array}$ & $\begin{array}{l}\text { EC meter, mixing } \\
\text { containers }\end{array}$ & 1 & 2 & 2 & 2 & 7 & yes \\
\hline
\end{tabular}

Float method streamflow measurements involve the following steps.

1. Select stream reach with straight and uniform flow.

2. Divide cross section into several subsections ( $n$, typically between 5 and 20).
3. For each subsection, measure and record the following.

a. The depth in the middle of the subsection.

b. The width of the subsection.

c. The time it takes a floating object to move a known distance downstream (typically 1 or $2 \mathrm{~m}$ ) in the middle of the subsection. 


\section{Solve for streamflow $(Q)$ with Eq. (1).}

Distances of 1 or $2 \mathrm{~m}$ were necessary to measure surface velocity for each subsection since it was unlikely that a float would stay in a single subsection for 10 or $20 \mathrm{~m}$. These shorter distances ensured that surface velocity measurements were representative of their respective subsections and associated areas. One benefit of this approach was that the measured surface velocities were cross-sectional-area weighted. This area weighting was more important as surface velocity differences between the center and the sides of the channel increased. Since these velocity differences vary from site to site, using a single float with a single coefficient (e.g., 0.8) would have ignored these differences among sites.

\subsubsection{Salt dilution method}

There are two basic types of salt dilution flow measurements: slug (previously known as instantaneous) and continuous rate (Moore, 2004a). Salt dilution measurements are based on the principle of the conservation of mass. In the case of the slug method, a single known volume of high-concentration salt solution is introduced to a stream and the electrical conductivity (EC) is measured over time at a location sufficiently downstream to allow good mixing (Moore, 2005). An approximation of the integral of EC as a function of time is combined with the volume of tracer and a calibration constant (Eq. 2) to determine discharge. In contrast, the continuous rate salt dilution method involves introducing a known flow rate of salt solution into a stream (Moore, 2004b). Slug method salt dilution measurements are broadly applicable in streams with flows up to $10 \mathrm{~m}^{3} \mathrm{~s}^{-1}$ with steep gradients and low background EC levels (Moore, 2005). For the sake of citizen scientist repeatability, we chose to only investigate the slug method, because of the added complexity of measuring the flow rate of the salt solution for the continuous rate method. Some limitations of the salt dilution method include (1) inadequate vertical and horizontal mixing of the tracer in the stream, (2) trapping of the tracer in slow-moving pools of the stream, and (3) incomplete dilution of salt within the stream water prior to injection. The first two limitations can be addressed with proper site selection (i.e., well-mixed reach with little slow-moving bank storage), while incomplete dilution can be avoided by proper training of the personnel performing the measurement.

Streamflow $\left(Q ; \mathrm{L} \mathrm{s}^{-1}\right)$ is solved for using Eq. (2) (Rantz, 1982; Moore, 2005):

$Q=\frac{V}{k \sum_{i=1}^{n}\left(\sigma(t)-\sigma_{\mathrm{BG}}\right) \Delta t}$,

where $V$ is the total volume of tracer introduced into the stream $(L), k$ is the calibration constant in centimeters per

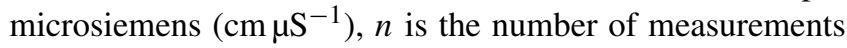
taken during the breakthrough curve (unitless), $\sigma(t)$ is the EC at time $t\left(\mu \mathrm{S} \mathrm{cm}^{-1}\right), \sigma_{\mathrm{BG}}$ is the background $\mathrm{EC}\left(\mu \mathrm{S} \mathrm{cm}^{-1}\right)$, and $\Delta t$ is the change in time between EC measurements (s).
Salt dilution method streamflow measurements involve the following steps.

1. Select stream reach with turbulence to facilitate vertical and horizontal mixing.

2. Determine upstream point for introducing the salt solution and a downstream point for measuring EC.

- A rule of thumb in the literature is to separate these locations roughly 25 stream widths apart (Day, 1977; Butterworth et al., 2000; Moore, 2005).

3. Estimate flow either by performing a "simplified float measurement" (i.e., only a few subsections) or by visually estimating width, average depth, and average velocity.

4. Prepare salt solution based on the following guidelines (approximate average of dosage recommendations from previous studies cited by Moore, 2005).

a. $10000 \mathrm{~mL}$ of stream water for every $1 \mathrm{~m}^{3} \mathrm{~s}^{-1}$ of estimated streamflow.

b. $1667 \mathrm{~g}$ of salt for every $1 \mathrm{~m}^{3} \mathrm{~s}^{-1}$ of estimated streamflow.

c. Thoroughly mix salt and water until all salt is dissolved.

d. Following these guidelines, ensure a homogenous salt solution with 1 to 6 salt to water ratio by mass.

5. Establish the calibration curve relating EC values to actual salt concentrations (Moore, 2004b) to determine the calibration constant $(k)$ relating changes in $\mathrm{EC}$ values in microsiemens per centimeter $\left(\mu \mathrm{S} \mathrm{cm}^{-1}\right)$ in the stream to relative concentration (RC) of introduced salt solution (see Sect. 2.3.3 for details).

6. Dump salt solution at upstream location.

7. Measure EC at downstream location during salinity breakthrough until values return to background EC.

- Record a video of the EC meter screen at the downstream location and later digitize the values using the time from the video and the EC values from the meter.

8. Solve for streamflow $(Q)$ with Eq. (2).

\subsubsection{Bernoulli run-up method}

Like the float method, Bernoulli run-up (or Bernoulli) is based on the velocity-area principle. The basic principle is that run-up on a flat plate inserted perpendicular to flow is proportional to velocity based on the solution to Bernoulli's equation. Bernoulli run-up is also referred to as the "velocity head rod" by Church and Kellerhals (1970), Carufel (1980), 
and Fonstad et al. (2005) and is similar to the "weir stick" discussed by USBR (2001). The velocity measurement theory of Bernoulli is similar to using a pitot tube (Almeida and de Souza, 2017), without the associated challenges of (1) using and transporting potentially bulky and fragile equipment and (2) clogging from sediment or trash (WMO, 2010). However, the accuracy and precision of the Bernoulli method velocity head measurements are likely lower than pitot measurements. Total streamflow $\left(Q ; \mathrm{L} \mathrm{s}^{-1}\right)$ is calculated with Eq. (3):

$Q=1000 \cdot \sum_{i=1}^{n} V_{B_{i}} \cdot d_{1_{i}} \cdot w_{i}$,

where 1000 is a conversion factor from $\mathrm{m}^{3} \mathrm{~s}^{-1}$ to $\mathrm{L} \mathrm{s}^{-1}, V_{B_{i}}$ is the velocity from Bernoulli run-up $\left(\mathrm{m} \mathrm{s}^{-1}\right), d_{1_{i}}$ is the depth $(\mathrm{m})$, and $w_{i}$ is the width $(\mathrm{m})$ of each subsection $(i=1$ to $n)$. Area for each subsection is the product of the width and the depth in the middle of each subsection. Velocity for each subsection $\left(V_{B_{i}}\right)$ was determined by measuring the run-up or change in water level on a thin meter stick (or "flat plate"; dimensions used in this study: $1 \mathrm{~m}$ long by $34 \mathrm{~mm}$ wide by $1.5 \mathrm{~mm}$ thick) from when the flat plate was inserted parallel and then perpendicular to the direction of flow. The parallel depth measurement represents the static head, while the perpendicular represents the total head. Velocity $\left(V_{B_{i}} ; \mathrm{m} \mathrm{s}^{-1}\right)$ is calculated from Bernoulli's principle with Eq. (4):

$V_{B_{i}}=\sqrt{2 g \cdot\left(d_{2_{i}}-d_{1_{i}}\right)}$

where $g$ is the gravitational constant $\left(\mathrm{m} \mathrm{s}^{-2}\right)$, and $d_{2_{i}}$ and $d_{1_{i}}$ are the water depths $(\mathrm{m})$ when the flat plate was perpendicular and parallel to the direction of flow, respectively.

Bernoulli method streamflow measurements involve the following steps.

1. Select constricted stream section with elevated velocity to increase the difference between $d_{1_{i}}$ and $d_{2_{i}}$.

2. Divide cross section into several subsections ( $n$, typically between 5 and 20).

3. For each subsection, measure and record the following.

a. The depth with a flat plate held perpendicular to flow ( $d_{2_{i}}$ or the run-up depth).

b. The depth with a flat plate held parallel to flow $\left(d_{1_{i}}\right.$ or the actual water depth).

c. The width of the subsection.

4. Solve for streamflow $(Q)$ with Eqs. (3) and (4).

\subsection{General items}

\subsubsection{Types of streams evaluated}

Streams evaluated during this investigation (phases 1, 2, and 3 ) were a mixture of pool and riffle, pool and drop, and run stream types. Streamflows ranged from 0.4 to $1804 \mathrm{~L} \mathrm{~s}^{-1}$. Stream widths and average depths ranged from 0.1 to $6.0 \mathrm{~m}$ and from 0.0040 to $0.97 \mathrm{~m}$, respectively. Streambed materials ranged from cobles, gravels, and sands in the upper portions of the watershed to sands, silts, and sometimes man-made concrete streambeds and side retaining walls in the lower portions. During pre-monsoon, sediment loads were generally low, while during post-monsoon increased water velocities led to increased sediment loads (both suspended and bed). Slopes (based on phase 2 data) ranged from 0.020 to $0.148 \mathrm{~m} \mathrm{~m}^{-1}$. Additional details about the measurement sites are provided in Tables 4 and 5. Since roughly $80 \%$ of Nepal's precipitation occurs during the summer monsoon (Nayava, 1974), pre- and post-monsoon represent periods of relatively low and high streamflows, respectively. Therefore, we consistently use pre-monsoon and post-monsoon to refer to the general seasons that phase 1,2 , and 3 activities were performed in.

\subsubsection{Reference flows}

To evaluate different simple citizen science flow measurement methods, reference (or actual) flows for each site were needed. We used a SonTek FlowTracker acoustic Doppler velocimeter (ADV) to determine reference flows. The United States Geological Survey (USGS) midsection method was used, following guidelines from USGS Water Supply Paper 2175 (Rantz, 1982), along with instrument-specific recommendations from SonTek's FlowTracker manual (SonTek, 2009). Stream depths were shallow enough that a single vertical 0.6 depth velocity measurement (i.e., $40 \%$ up from the channel bottom) was used to measure average velocity for each subsection (Rantz, 1982). While there is uncertainty in using the 0.6 depth as representative of average velocity, Rantz (1982) states that "actual observation and mathematical theory have shown that the 0.6 depth method gives reliable results" for depths less than $0.76 \mathrm{~m}$; multipoint methods are not recommended for depths less than $0.76 \mathrm{~m}$, so this is the recommended USGS approach. Depending on the total width of the channel, the number of subsections ranged from 8 to 30. The FlowTracker ADV has a stated velocity measurement accuracy of within $1 \%$ (SonTek, 2009). Based on an ISO discharge uncertainty calculation within the SonTek FlowTracker software, the uncertainties in reference flows for phases 1 and 2 ranged from $2.5 \%$ to $8.2 \%$, with a mean of $4.2 \%$. Based on the literature (Rantz, 1982; Harmel, 2006; Herschy, 2009), these uncertainties in reference flows are towards the lower end of the expected range for field measurements of streamflow. Therefore, we do not think that any systematic biases or uncertainties in our data change the results of this paper. A compilation of the measurement reports generated by the FlowTracker ADV, including summaries of measurement uncertainty, is included in the Supplement. 


\subsubsection{Salt dilution calibration coefficient $(k)$}

Our experience was that the most complicated portion of a salt dilution measurement was performing the dilution test to determine the calibration coefficient $k$. The calibration coefficient $k$ relates changes in EC values in microsiemens per centimeter $\left(\mu \mathrm{S} \mathrm{cm}^{-1}\right)$ in the stream to relative concentrations of introduced salt solution (RC). During phases 1 and 2 , we determined $k$ using a calibrated GHM 3431 (GHMGreisinger) EC meter with the procedure recommended by Moore (2004b; additional details are included in the Supplement).

Due to the challenges of measuring $k$ in the field, especially for citizen scientists who are the ultimate target for performing these streamflow measurements, average $k$ values were used to determine salt dilution streamflows. For phase 1 , an average $k$ of $2.79 \times 10^{-6} \mu \mathrm{S} \mathrm{cm}^{-1} \mu \mathrm{S} \mathrm{cm}^{-1}(n=$ 10) was used for all 20 measurement sites (Table 4). For phase 2, an average $k$ of $2.95 \times 10^{-6} \mu \mathrm{S} \mathrm{cm}^{-1}(n=15)$ was used for all 15 sites (Table 5). For phase 3, the phase 2 average $k$ of $2.95 \times 10^{-6} \mu \mathrm{S} \mathrm{cm}^{-1}$ was used to calculate streamflows for all salt dilution measurements. The impact of using average $k$ values on salt dilution measurements is discussed in Sect. 4.1. Moore (2005) suggests that $k$ is a function of (1) the ratio of salt and water in the tracer solution and (2) the chemical composition of the stream water. To minimize variability in $k$ due to changes in salt concentration, a fixed ratio of salt to water (i.e., 1 to 6 by mass) was used to prepare tracer solutions for all phases of this investigation.

\subsubsection{Inexpensive EC meters}

For phases 2 and 3, 10 inexpensive (i.e., USD 15) water quality testers (HoneForest) were used to measure EC for salt dilution measurements. To evaluate the accuracy of these meters, we performed a six-point comparison test with reference EC values of $20,107,224,542,1003$, and $1517 \mu \mathrm{sm}^{-1}$, as determined by a calibrated GHM 3431 (GHM-Greisinger) EC meter. EC measurements were performed from low EC to high EC (for all six points) and were repeated three times for each meter. Because EC is used to compute the integral of the breakthrough curve (Eq. 2), the percent difference (i.e., error) in EC changes between the six points (i.e., five intervals) from the inexpensive meters was compared to reference EC intervals (Fig. 1). Based on this analysis, the inexpensive meters had a positive median bias of roughly $5 \%$ (ranging from $-14 \%$ to $21 \%$ ) for $\mathrm{EC}$ value changes between 20 and $542 \mu \mathrm{S} \mathrm{cm}^{-1}$ (i.e., D1, D2, and D3). A nearly zero median bias (ranging from $-5 \%$ to $5 \%$ ) for $\mathrm{EC}$ value changes between 542 and $1003 \mu \mathrm{S} \mathrm{cm}^{-1}$ (i.e., D4) was present. Finally, there was a negative median bias of roughly $-9 \%$ (ranging from $-18 \%$ to $6 \%$ ) for $\mathrm{EC}$ value changes between 1003 and $1517 \mu \mathrm{S} \mathrm{cm}^{-1}$ (i.e., D5). No corrections were made to EC measurements collected with inexpensive (HoneForest) EC meters.

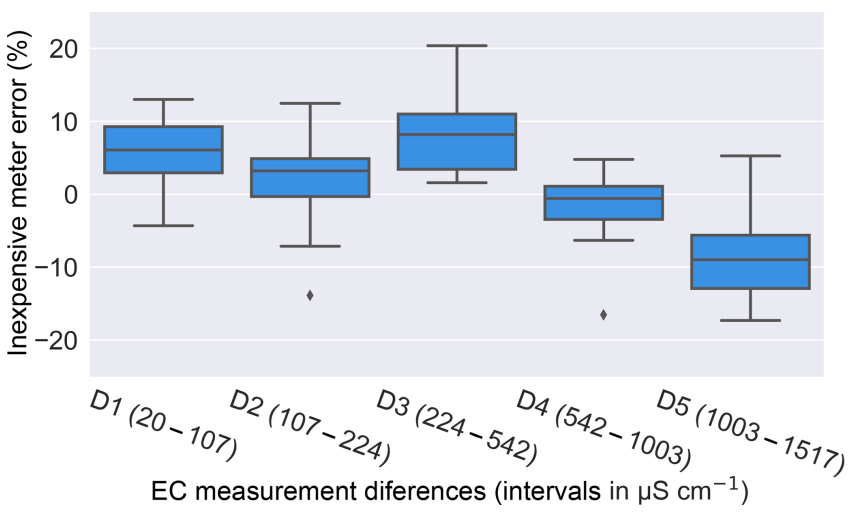

Figure 1. Box plots of inexpensive water quality tester (HoneForest) errors for five different intervals (i.e., D1 to D5). The ranges of EC values from reference EC measurements (determined by a calibrated GHM 3431 (GHM-Greisinger) EC meter) are shown in parentheses in $\mu \mathrm{S} \mathrm{cm}^{-1}$. Boxes show the interquartile range between the first and third quartiles of the dataset, while whiskers extend to show minimum and maximum values of the distribution, except for points that are determined to be outliers (shown as diamonds), which are more than 1.5 times the interquartile range away from the first or third quartiles.

\subsection{Phases of the investigation}

This investigation was carried out in three distinct phases including phase 1 - initial evaluation, phase 2 - citizen scientist evaluation, and phase 3 - citizen scientist application (Table 2).

\subsubsection{Initial evaluation (phase 1)}

For phase 1 evaluation of the three simple streamflow measurement methods, we performed sets of measurements at 20 sites within the Kathmandu Valley, Nepal (Fig. 2a and b). The Kathmandu Valley is a small intermontane basin roughly $25 \mathrm{~km}$ in diameter with a total area of $587 \mathrm{~km}^{2}$ in the central region of Nepal and encompasses most of the Kathmandu, Bhaktapur, and Lalitpur districts. Figure $2 \mathrm{c}$ is a photograph of the typical types of relatively steep pool and drop stream systems included in phase 1 . Sites were chosen to represent a typical range of stream types, slopes, and flow rates. At each site, we performed float, salt dilution, and Bernoulli measurements, in addition to reference flow measurements with the FlowTracker ADV as per the descriptions in Sect. 2.2 and 2.3.2, respectively. All phase 1 salt dilution EC measurements were taken with a calibrated GHM 3431 (GHMGreisinger) EC meter.

At each site, measurements were performed consecutively and took roughly 1 to $2 \mathrm{~h}$ to perform, depending on the size of the stream and the resulting number of subsections for float, Bernoulli, and reference flow measurements. Measurements were performed during steady-state conditions in the stream; if runoff-generating precipitation occurred during measure- 
Table 2. Brief descriptions of three data collection phases including who performed the field data collection and what period and season the data were collected in.

\begin{tabular}{|c|c|c|c|c|c|}
\hline No. & Phase & Description & Performed by & Period & Season \\
\hline 1 & Initial evaluation & $\begin{array}{l}\text { Initial evaluation of three sim- } \\
\text { ple flow measurement meth- } \\
\text { ods (i.e., float, salt dilution, } \\
\text { and Bernoulli) along with } \\
\text { FlowTracker ADV reference } \\
\text { flow measurements at } 20 \text { sites } \\
\text { within the Kathmandu Valley. } \\
\text { Reference flows ranged from } \\
6.4 \text { to } 240 \mathrm{~L} \mathrm{~s}^{-1} \text {. }\end{array}$ & Authors & March/April 2017 & Pre-monsoon \\
\hline 2 & $\begin{array}{l}\text { Citizen scientist } \\
\text { evaluation }\end{array}$ & $\begin{array}{l}\text { Citizen scientist evaluation of } \\
\text { three simple flow measure- } \\
\text { ment methods (i.e., float, salt } \\
\text { dilution, and Bernoulli) along } \\
\text { with expert and FlowTracker } \\
\text { ADV reference flow measure- } \\
\text { ments at } 15 \text { sites within the } \\
\text { Kathmandu Valley. Reference } \\
\text { flows ranged from } 4.2 \text { to } \\
896 \mathrm{~L} \mathrm{~s}^{-1} \text {. }\end{array}$ & $\begin{array}{l}\text { Authors for expert and refer- } \\
\text { ence flows plus } 10 \text { Citizen Sci- } \\
\text { ence Flow groups for simple } \\
\text { methods }\end{array}$ & September 2018 & $\begin{array}{l}\text { Post- } \\
\text { monsoon }\end{array}$ \\
\hline 3 & $\begin{array}{l}\text { Citizen scientist } \\
\text { application }\end{array}$ & $\begin{array}{l}\text { Salt dilution measurements at } \\
\text { roughly } 130 \text { sites in the } 10 \\
\text { perennial watersheds of the } \\
\text { Kathmandu Valley. Float mea- } \\
\text { surements with a small num- } \\
\text { ber of subsections (e.g., three } \\
\text { to five) performed at each site } \\
\text { to determine salt dosage. Ob- } \\
\text { served flows ranged from } 0.4 \\
\text { to } 425 \mathrm{~L} \mathrm{~s}^{-1} \text { and from } 1.1 \text { to } \\
1804 \mathrm{~L} \mathrm{~s}^{-1} \text { in pre and post- } \\
\text { monsoon, respectively. }\end{array}$ & $\begin{array}{l}18 \text { Citizen Science Flow } \\
\text { groups ( } 8 \text { from April and } 10 \\
\text { from September) }\end{array}$ & April and September 2018 & $\begin{array}{l}\text { Pre- and post- } \\
\text { monsoon }\end{array}$ \\
\hline
\end{tabular}

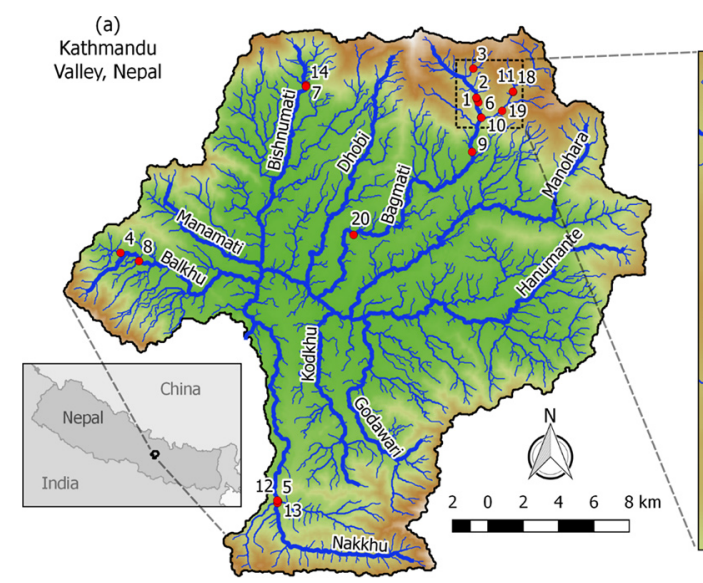

(b) Zoomed area northeast of Kathmandu

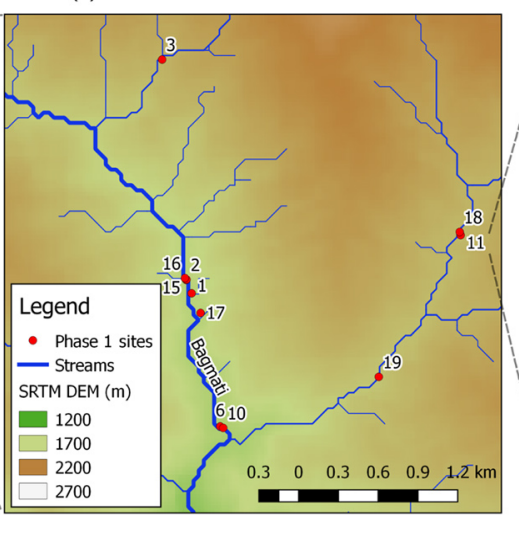

(c) Photograph of site 11

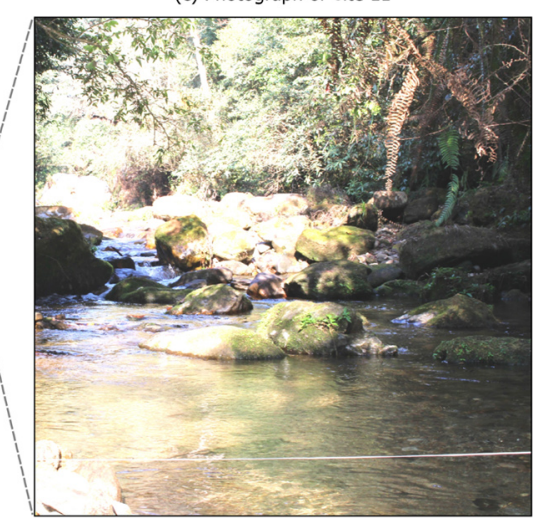

Figure 2. Map showing topography of the Kathmandu Valley from a Shuttle Radar Topography Mission (SRTM, 2000) digital elevation model (DEM), the resulting stream network (Davids et al., 2018), and locations of phase 1 measurement sites (a). Names of the 10 historically perennial tributaries are shown. (b) shows an enlarged view of the area where 11 of the 20 measurements were taken. (c) is a photograph of site 11 , a pool and riffle sequence flowing at roughly $100 \mathrm{~L} \mathrm{~s}^{-1}$. Measurement sites are labeled with phase 1 site IDs. 
ments at a site, the measurements were stopped and then repeated after streamflows stabilized at pre-event levels. As previously described, the salt dilution calibration coefficient $k$ was determined at 10 of the 20 sites. Field notes for float, salt dilution, and Bernoulli methods were taken manually and later digitized into a spreadsheet (included in the Supplement). Results from phase 1 are summarized in tabular form (Table 4). To understand relative (normalized) errors, we calculated percent differences in relation to reference flow for each method. Averages of absolute value percent differences (absolute errors), average errors (bias), and standard deviations of errors were used as metrics to compare results among methods and between phases 1 and 2 .

\subsubsection{Citizen scientist evaluation (phase 2)}

To evaluate the same three streamflow measurement methods with actual citizen scientists, we recruited 37 student volunteers from Khwopa College of Engineering in Bhaktapur, Nepal, for our Citizen Science Flow (CS Flow) evaluation. A total of 10 CS Flow evaluation groups of either three or four members were formed. Citizen scientists were second- and third-year civil engineering bachelor's degree students ranging in age from 21 to $25 ; 12$ were female and 25 were male. Phase 2 citizen scientist evaluations (Fig. 3) were performed at seven sites in the Dhobi watershed in the north (Fig. 3b; D1 to D7) and eight sites in the Nakkhu watershed in the south (Fig. 3c; N1 to N8). Sites were chosen to represent a typical range of stream types, slopes, and flow rates found within the headwater catchments of the Kathmandu Valley and to minimize travel time between locations.

Phase 2 started on 17 September 2018 with a 4 h theoretical training on the float, salt dilution, and Bernoulli streamflow measurement methods as per Sect. 2.2. The theoretical training also introduced citizen scientists to Open Data Kit (ODK; Anokwa et al., 2009), a freely available open-source software for collecting and managing data in low-resource settings. ODK was used with the specific streamflow measurement workflow described below.

Based on our initial experiences and results from phase 1, we developed an ODK form to facilitate the collection of float, salt dilution, Bernoulli, and reference streamflow measurement data. After installing ODK on an Android smartphone and downloading the necessary form from S4WNepal's ODK Aggregate server on the Google Cloud App Engine, the general workflow is included in the Supplement.

Training was continued on 18 September with a $2 \mathrm{~h}$ field demonstration session in the Dhobi watershed located in the north of the Kathmandu Valley. During this field training, we worked with three to four groups at a time and together performed float, salt dilution, and Bernoulli measurements at site D3.

Following the field training, a Google My Map with the 15 sites was provided to the citizen scientists. Groups were strictly instructed to not discuss details regarding the selec- tion of measurement reaches or the results of the streamflow measurements with other groups. For the remainder of 18 September and all of 19 September, the 10 CS Flow groups rotated between the seven sites in the Dhobi watershed. To ensure that measurements could be compared with each other, four S4W-Nepal interns traveled between sites to verify that CS Flow groups performed measurements on the same streams in the same general locations. All eight measurements on the Nakkhu watershed were performed in similar fashion on 20 September.

Using the same schedule of the CS Flow groups, the expert group visited the same 15 sites. At each site, in addition to performing float, salt dilution, and Bernoulli measurements, the expert group performed (1) reference flow measurements as per Sect. 2.3.2, (2) salt dilution calibration coefficient $k$ dilution measurements as per Sect. 2.3.3, and (3) an autolevel survey to determine average stream slope. At each site, auto-level surveys included topographical surveys of stream water surface elevations with a 24X Automatic Level AT-B4 (Topcon) at five locations including 10 times and 5 times the stream width upstream of the reference flow measurement site (reference site), at the reference site, and 5 and 10 times the stream width downstream of the reference site. For each site, stream slope was taken as the average of the four slopes computed from the five water surface elevations measured.

All CS Flow and expert measurements were conducted under steady-state conditions. Based on two S4W-Nepal citizen scientists' precipitation measurements (official government records are not available until the subsequent year) nearby the Dhobi sites (i.e., roughly $3 \mathrm{~km}$ to the west and east), no measurable precipitation occurred during 18 and 19 September. Water level measurements from a staff gauge installed at site D3 taken at the beginning and end of 18 and 19 September confirmed that water levels (and therefore flows) remained steady. On 20 September, $7 \mathrm{~mm}$ of precipitation was recorded by a S4W-Nepal citizen scientist in Tikabhairab, which is roughly $1 \mathrm{~km}$ north of the eight measurement sites in the Nakkhu watershed. Based on field observations of the expert group, rain did not start until 15:30 LT, and all CS Flow group measurements were completed before 15:30 LT. Three expert measurement sites were completed after 15:30 LT, but most rain was concentrated downstream (to the north) of these sites (i.e., N1, N2, and N3). Based on water level measurements performed at the beginning, middle, and end of measurements at these sites, no changes in water levels (and therefore flows) were observed. We also do not see any systematic impacts to the resulting comparison data for these sites (Table 5 and Fig. 4).

Once ODK forms from all 15 sites were finalized and submitted to the ODK Aggregate server, CS Flow and expert groups digitized breakthrough curves (i.e., time and EC) from EC videos in shared Google Sheets salt dilution flow calculators. Digitizations for all measurements were then reviewed for accuracy and completeness by the authors. 

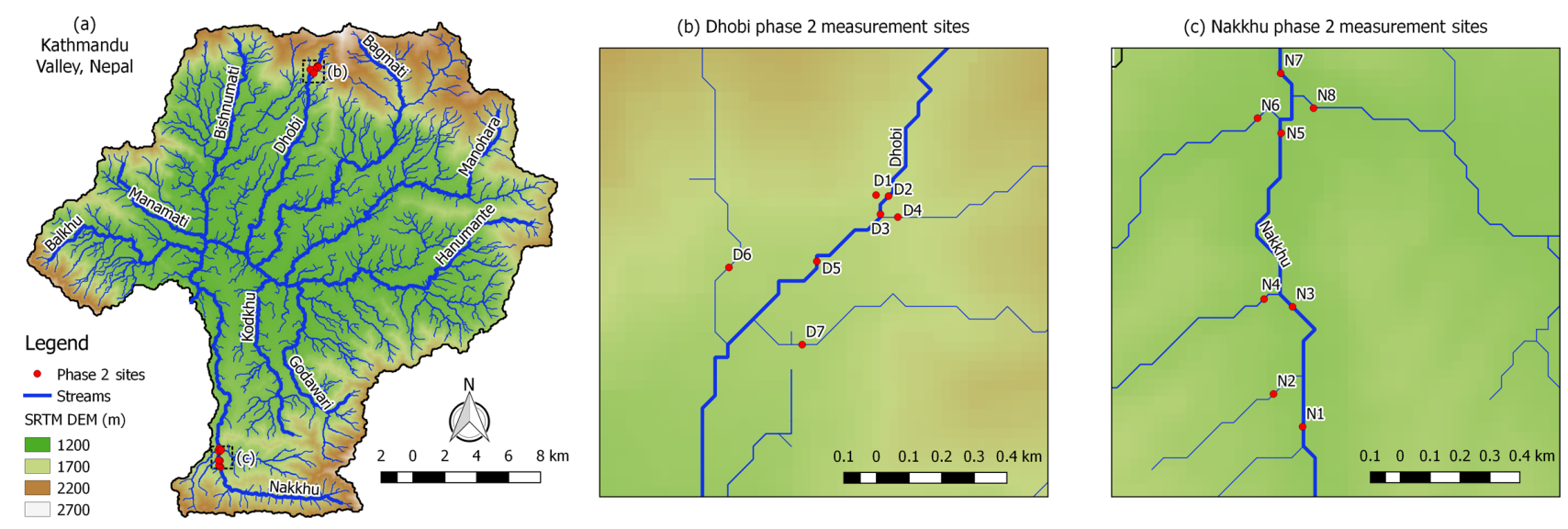

Figure 3. Map showing topography of the Kathmandu Valley, stream network, and locations of phase 2 measurement sites (a). Names of the 10 historically perennial tributaries are shown. (b) shows an enlarged view of the upper Dhobi watershed where phase 2 measurements D1 through D7 were performed. (c) shows an enlarged view of the middle Nakkhu watershed where phase 2 measurements N1 through N8 were performed. Measurement sites are labeled with phase 2 site IDs.

After the completion of phase 2 field work, a Google Forms survey was completed by 33 of the phase 2 citizen scientists (Table 3). The purpose of the survey was to evaluate citizen scientists' perceptions of the three simple streamflow measurement methods. The survey questions forced participants to rank each method from 1 to 3 . Questions were worded so that in all cases a rank of 1 was most favorable and 3 was least favorable.

A tabular summary of the 15 phase 2 measurement locations was developed (Table 5). To understand relative (normalized) errors, we calculated percent differences in relation to reference flow for each method. Averages of absolute value percent differences (absolute errors), average errors (bias), and standard deviations of errors were used as metrics to compare results among methods and between phase 1 and 2. Box plots showing the distribution of CS Flow group measurement errors along with expert measurement errors for each method were developed (Fig. 4). To visualize the results of the citizen scientists' perception survey, a stacked horizontal bar plot grouped by streamflow measurement methods was developed (Fig. 5).

\subsubsection{Citizen scientist application (phase 3)}

From 15 to 21 April 2018 (pre-monsoon) and from 21 to 25 September 2018 (post-monsoon), 25 and 37 second- and third-year engineering bachelor's degree student citizen scientists, respectively, from Khwopa College of Engineering in Bhaktapur, Nepal, joined S4W-Nepal's Citizen Science Flow campaign. Citizen scientists formed 8 pre-monsoon and 10 post-monsoon CS Flow groups of three or four people each. Ages of pre-monsoon citizen scientists ranged from 21 to 25; 7 were female and 18 were male (post-monsoon group composition is described in Sect. 2.4.2).
Post-monsoon phase 3 measurements were performed by the same 10 CS Flow groups that performed phase 2 citizen scientist evaluations. Therefore, additional training for these groups was not necessary. Training for pre-monsoon CS Flow groups included a $4 \mathrm{~h}$ theoretical training on 15 April about the float and salt dilution streamflow measurement methods as per Sect. 2.2. The theoretical training also introduced citizen scientists to ODK Android data collection application. For both pre- and post-monsoon phase 3 measurements, the workflow was similar to that described in Sect. 2.4.2 (see the Supplement for details), with the exceptions of (1) skipping collection of Bernoulli data and (2) only performing a simplified float measurement involving only two or three subsections in order to have a flow estimate for calculating the recommended salt dose. Training was continued on the afternoon of 15 April with a $2 \mathrm{~h}$ field demonstration session in the Hanumante watershed located in the southwestern portion of the Kathmandu Valley (Fig. 6). During this field training, we worked with four groups at a time and together performed simplified float and Bernoulli measurements at two sites.

After training was completed, citizen scientists were sent to the field to perform streamflow measurements as described above in all 10 headwater catchments of the Kathmandu Valley (Fig. 6). All phase 3 salt dilution EC breakthrough curve measurements were performed with inexpensive (HoneForest) meters. Once ODK forms from all phase 3 measurements were finalized and submitted to the ODK Aggregate server, CS Flow groups digitized breakthrough curves (i.e., time and EC) from EC videos in shared Google Sheets salt dilution flow calculators. Digitizations for all measurements were then reviewed for accuracy and completeness by the authors. While not included in this paper, it is important to note that students analyzed the collected flow data and finally presented oral and written summaries of their quality-controlled 
(a) Float method

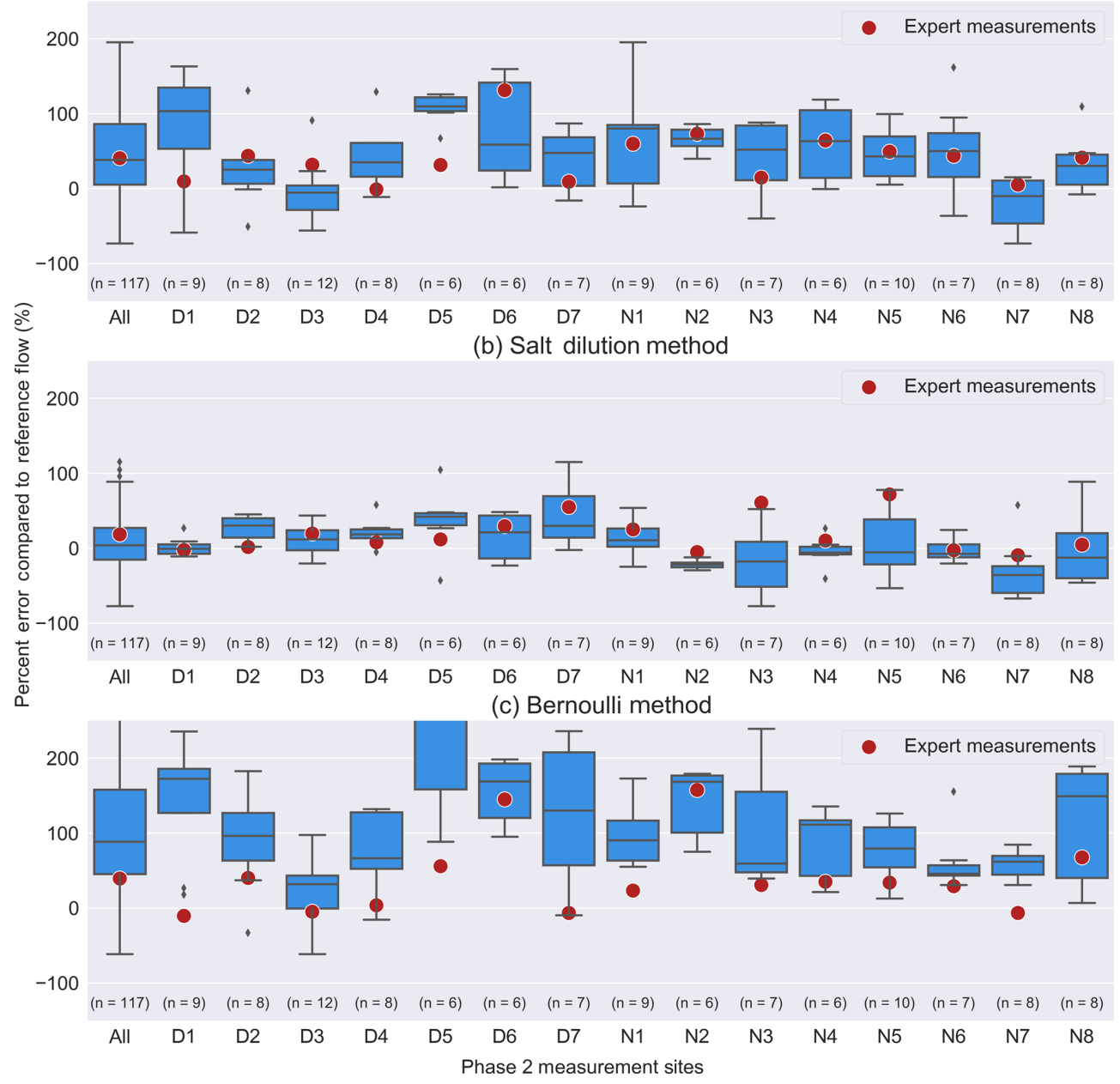

Figure 4. Box plots showing distribution of CS Flow group percent errors compared to reference flows for (a) float, (b) salt dilution, and (c) Bernoulli streamflow measurement methods. A summary of "all" measurements followed by the 15 phase 2 measurement sites (i.e., D1 to D7 in the Dhobi watershed and N1 to N8 in the Nakkhu watershed) is shown on the horizontal axes. Percent errors for expert measurements for each site and method are shown as red circles. The expert measurements shown for "all" are the mean of all expert measurements for each method. Sample sizes for each method and each site are shown in parentheses above each site label. Boxes show the interquartile range between the first and third quartiles of the dataset, while whiskers extend to show minimum and maximum values of the distribution, except for points that are determined to be outliers (shown as diamonds), which are more than 1.5 times the interquartile range away from the first or third quartiles. To facilitate comparison between sub-panels, vertical axes are fixed from $-150 \%$ to $250 \%$. In certain cases, portions of the error distribution are outside of the fixed range (e.g., site D5 for the Bernoulli method, c).

Table 3. Summary of phase 2 survey questions and the meanings of ranks.

\begin{tabular}{llll}
\hline No. & Question & $\begin{array}{l}\text { Rank 1 } \\
\text { meaning }\end{array}$ & $\begin{array}{l}\text { Rank 3 } \\
\text { meaning }\end{array}$ \\
\hline Q1 & Required training for each method & Least & Most \\
Q2 & Cost of equipment for each method & Least & Most \\
Q3 & Number of citizen scientists required for each method & Least & Most \\
Q4 & Data-recording requirements for each method & Least & Most \\
Q5 & Complexity of procedure for each method & Least & Most \\
Q6 & Enjoyability of measurement method & Most & Least \\
Q7 & Safety of each method & Most & Least \\
Q8 & Accuracy of each method & Most & Least \\
\hline
\end{tabular}



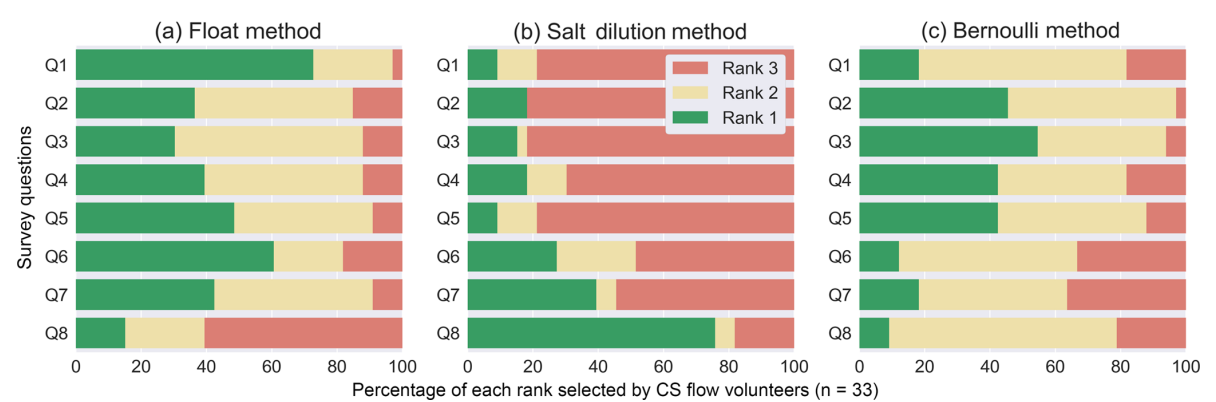

Figure 5. Results of the CS Flow group perception questions for (a) float, (b) salt dilution, and (c) Bernoulli methods. Questions Q1 through Q8 are shown on the vertical axis. Percentages of each rank selected by CS Flow citizen scientists $(n=33)$ are shown on the horizontal axis. Questions were worded so that in all cases a rank of 1 was most favorable and 3 was least favorable. Questions are as follows (also included in Table 3): Q1 - required training (rank 1 meaning least and 3 most); Q2 - cost of equipment (rank 1 meaning least and 3 most); Q3 number of citizen scientists required (rank 1 meaning least and 3 most); Q4 - data-recording requirements (rank 1 meaning least and 3 most); Q5 - complexity of procedure (rank 1 meaning least and 3 most); Q6 - enjoyability of measurement (rank 1 meaning most and 3 least); Q7 - safety (rank 1 meaning most and 3 least); Q8 - accuracy (rank 1 meaning most and 3 least).
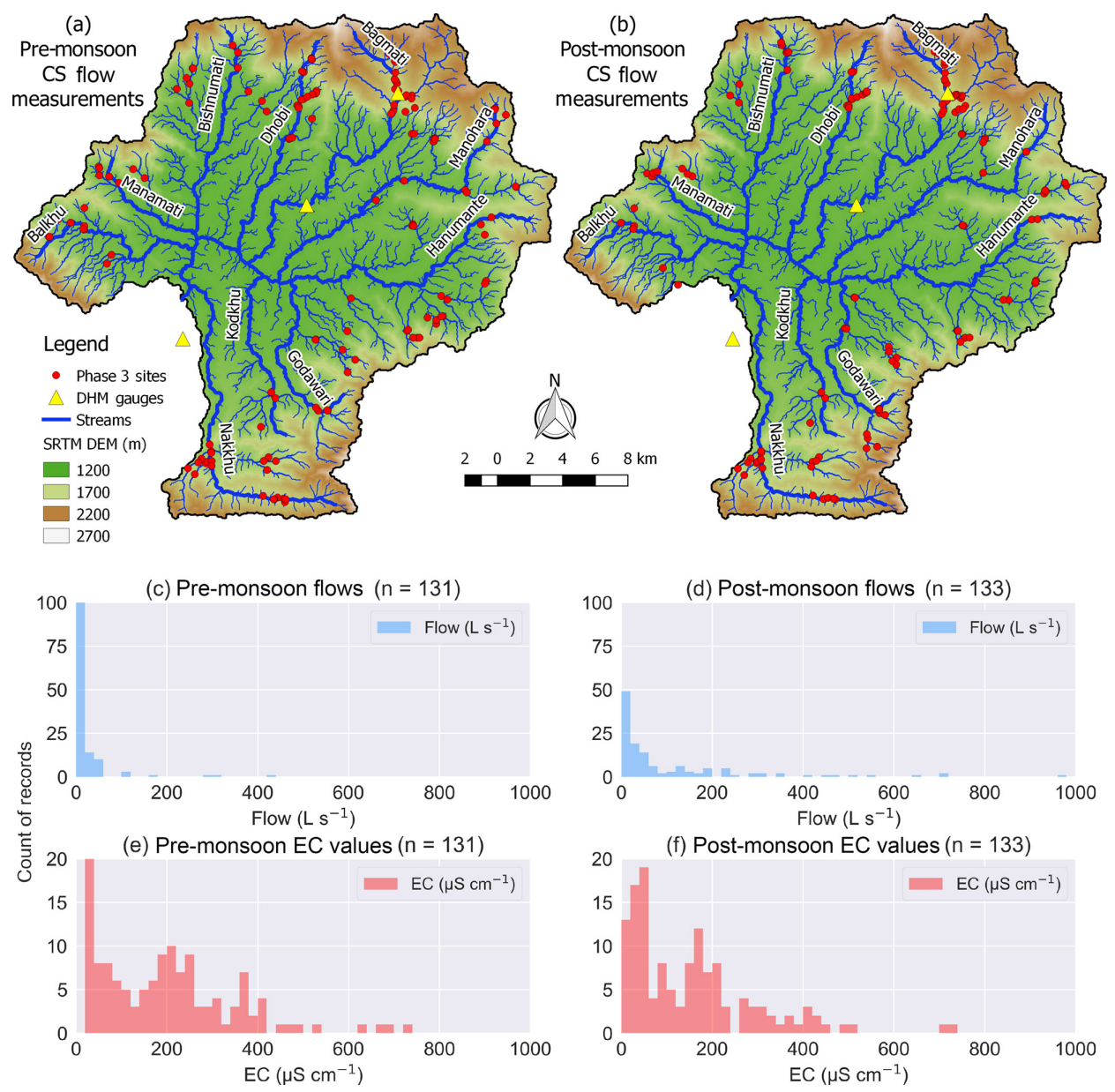

Figure 6. CS Flow campaign measurement locations ( $n=131$ pre-monsoon; $n=133$ post-monsoon) within the Kathmandu Valley for (a) pre- and (b) post-monsoon. Histograms show distributions of measured flows in $\mathrm{L} \mathrm{s}^{-1}$ (c, d) and EC in $\mu \mathrm{S} \mathrm{cm}^{-1}$ (e, f). Bins are set to 20 units wide for both flow and EC. Three flow measurements for the post-monsoon (d) that were above $1000 \mathrm{~L} \mathrm{~s}^{-1}$ are not shown: 1059 , 1287 , and 1804. Three Department of Hydrology and Meteorology (DHM) gauging stations are shown as yellow triangles. 
results to their faculty and peers at Khwopa College of Engineering.

While subsequent work will highlight the knowledge about spring and streamflows gained from these data, the purpose herein is more a proof of concept showing that the salt dilution method can be successfully applied at more sites with more people. As such, a simple map figure is used to show the spatial distribution of measurements. The three streamflow gauging stations within the Kathmandu Valley (only one in a headwater catchment) operated by the official government agency responsible for streamflow measurements (i.e., the Department of Hydrology and Meteorology or DHM) are also included. Additionally, histograms of flow and EC for pre- and post-monsoon are also shown. While measurements in pre- and post-monsoon were not all taken in the same locations, histograms can still be used to see seasonal changes in distributions.

\section{Results}

The following results section is organized into the same three phases included in the methodology (Sect. 2.4): initial evaluation (phase 1), citizen scientist evaluation (phase 2), and citizen scientist flow application (phase 3 ).

\subsection{Initial evaluation results (phase 1)}

Reference flows evaluated in phase 1 ranged from 6.4 to $240 \mathrm{~L} \mathrm{~s}^{-1}$ (Table 4; sorted in ascending order by reference flow). Elevations of measurements ranged from 1313 to 1905 ma.s.l. (meters above sea level). Salt dilution cali-

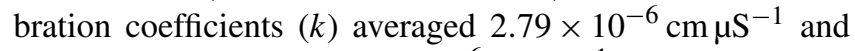

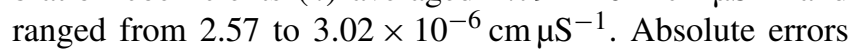
with respect to reference flows averaged $23 \%, 15 \%$, and $37 \%$, while biases for all methods were positive, averaging $8 \%, 6 \%$, and $26 \%$ for float, salt dilution, and Bernoulli methods, respectively. Standard deviations of errors were $29 \%, 19 \%$, and $62 \%$ for float, salt dilution, and Bernoulli methods, respectively. The largest salt dilution errors occurred for reference flows of $21 \mathrm{~L} \mathrm{~s}^{-1}$ or less (i.e., sites 1 through 7), while float and Bernoulli errors were more evenly distributed throughout the range of observed flows. Field notes from Bernoulli flow measurements for two measurements (site IDs 9 and 19) were destroyed by water damage, so Bernoulli flow and percent difference data were not available for these sites. Detailed reports for reference flow measurements along with calculations for each simplified streamflow measurement method are included in the Supplement.

\subsection{Citizen scientist evaluation results (phase 2)}

Reference flows evaluated in phase 2 ranged from 4.2 to $896 \mathrm{~L} \mathrm{~s}^{-1}$ (Table 5). Absolute errors for expert measurements averaged $41 \%, 21 \%$, and $43 \%$, while biases for all methods were positive, averaging $41 \%, 19 \%$, and $40 \%$ for float, salt dilution, and Bernoulli methods, respectively (Table 5 and Fig. 4). Standard deviations of expert errors were $34 \%, 26 \%$, and $51 \%$ for float, salt dilution, and Bernoulli methods, respectively. Salt dilution calibration coefficients

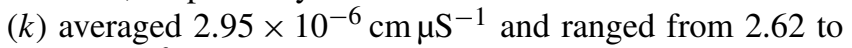
$3.42 \times 10^{-6} \mathrm{~cm} \mathrm{\mu S}^{-1}$. Measurement sites in the Dhobi watershed were pool and drop stream types, with slopes ranging from 0.076 to $0.148 \mathrm{~m} \mathrm{~m}^{-1}$. Streambeds for these sites were predominantly cobles, gravels, and sands. Smaller tributaries measured in the Nakkhu watershed (N2, N4, and N6) were also pool and drop stream types with slopes of $0.105,0.091$, and $0.055 \mathrm{~m} \mathrm{~m}^{-1}$, respectively. The remainder of the sites in the Nakkhu watershed were pool and riffle stream types with slopes ranging from 0.020 to $0.075 \mathrm{~m} \mathrm{~m}^{-1}$.

Box plots of CS Flow group errors combined with expert measurement errors for float (a), salt dilution (b), and Bernoulli (c) methods show that errors, for both expert and CS Flow groups, are smallest for the salt dilution method (Fig. 4). The number of CS Flow group measurements used to develop individual box plots ranged from 6 to 12 for each site and totalled 117 for all 15 sites. Two groups measured site D3 twice, so even though there were only 10 groups, there were 12 measurements available for comparison for this site. For the remainder of sites (except N5), problems with either capturing, compressing, uploading, or interpreting the video of EC used for determining salt dilution flow limited the number of usable measurements to less than the number of groups (i.e., 10). Absolute errors for CS Flow group measurements averaged $63 \%, 28 \%$, and $131 \%$, while biases for all methods were positive, averaging $52 \%, 7 \%$, and $127 \%$ for float, salt dilution, and Bernoulli methods, respectively. Standard deviations of CS Flow group errors were $82 \%, 36 \%$, and $225 \%$ for float, salt dilution, and Bernoulli methods, respectively.

For the float method (Fig. 4a), 13 median CS Flow group errors were positive, while two sites (i.e., D3 and N7) were negative. Float expert errors (i.e., red circles) were within the interquartile range (IQR; blue boxes between the first and third quartile) of CS Flow group errors for 10 out of 15 sites. One float expert error and $21 \mathrm{CS}$ Flow group errors were over $100 \%$. Float error medians and distributions were more variable in the Dhobi watershed than the Nakkhu watershed. For the salt dilution method (Fig. 4b), seven median CS Flow group errors were positive, while eight were negative. Salt dilution expert errors (i.e., red circles) were within the IQR of CS Flow group errors for 7 out of 15 sites. Zero salt dilution expert errors and two CS Flow group errors were over $100 \%$. Salt dilution error distributions were more compact for the Dhobi watershed compared to the Nakkhu watershed. For the Bernoulli method (Fig. 4c), all 15 median CS Flow group errors were positive. Bernoulli expert errors (i.e., red circles) were within the IQR of CS Flow group errors for 3 out of 15 sites. Two Bernoulli expert errors and 50 CS Flow group errors were over $100 \%$. Similar to float results, 


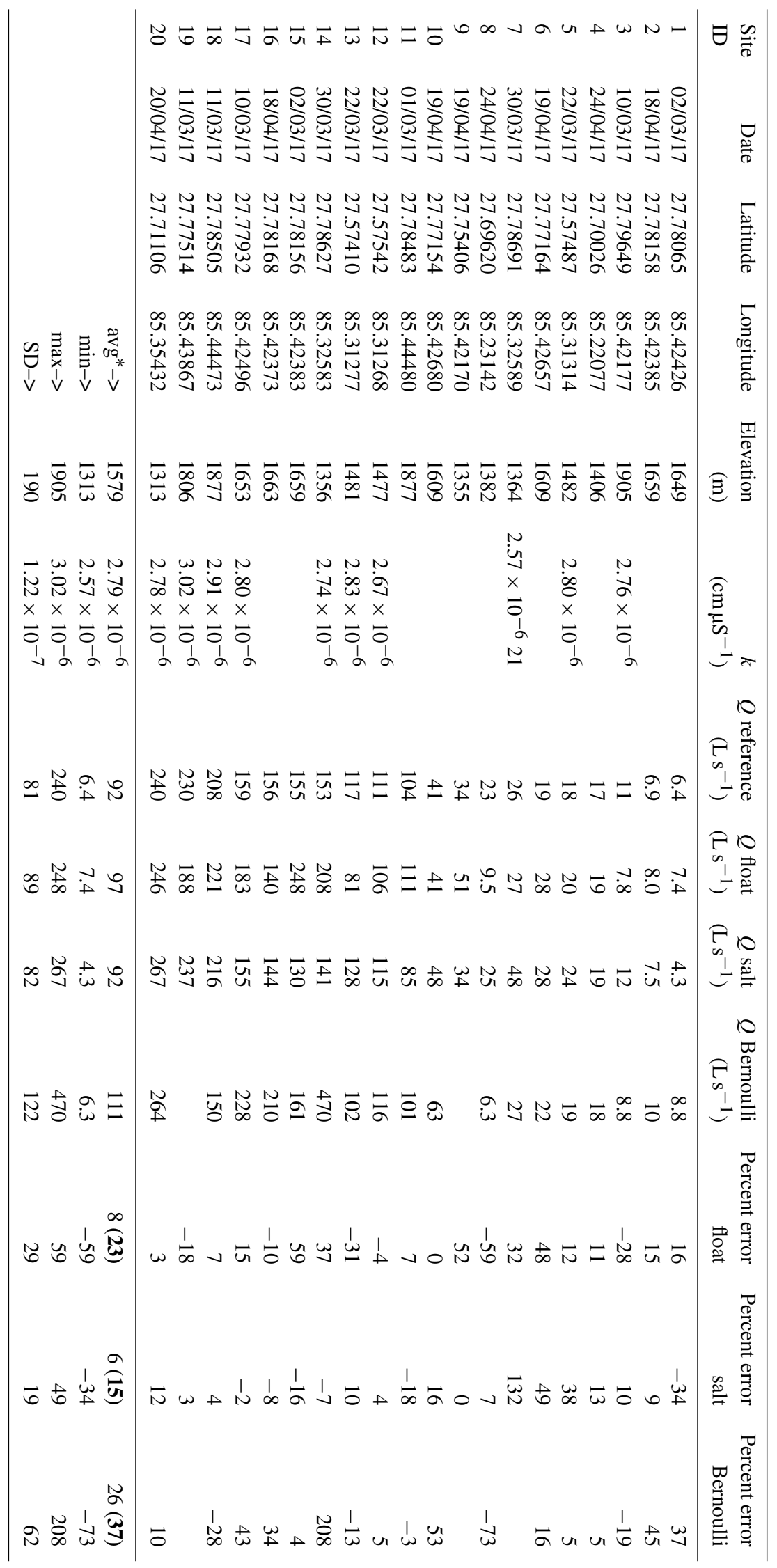

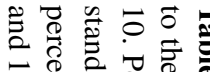

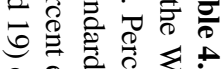

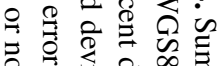

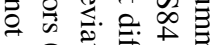

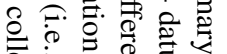

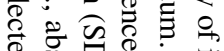
눌 ज行 की के 局 C. n ¿ 施. 它 त产. 10 号

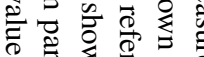
क्र

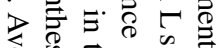
요용

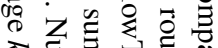
तิ

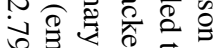
$\times$ 进芯志 कर

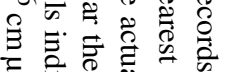
हो : 1 苍

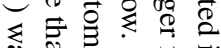
के

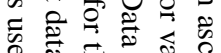
记 ○े $\oint$ 를 쿨

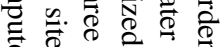

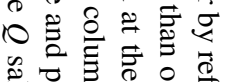
象实 웅

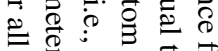
눙 $\overrightarrow{0}$ ¿े

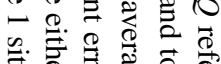

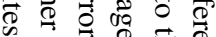

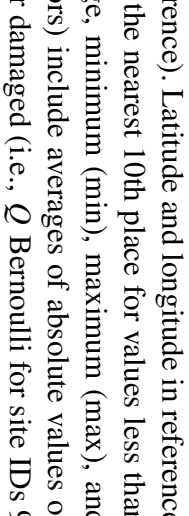

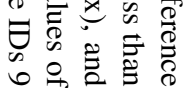




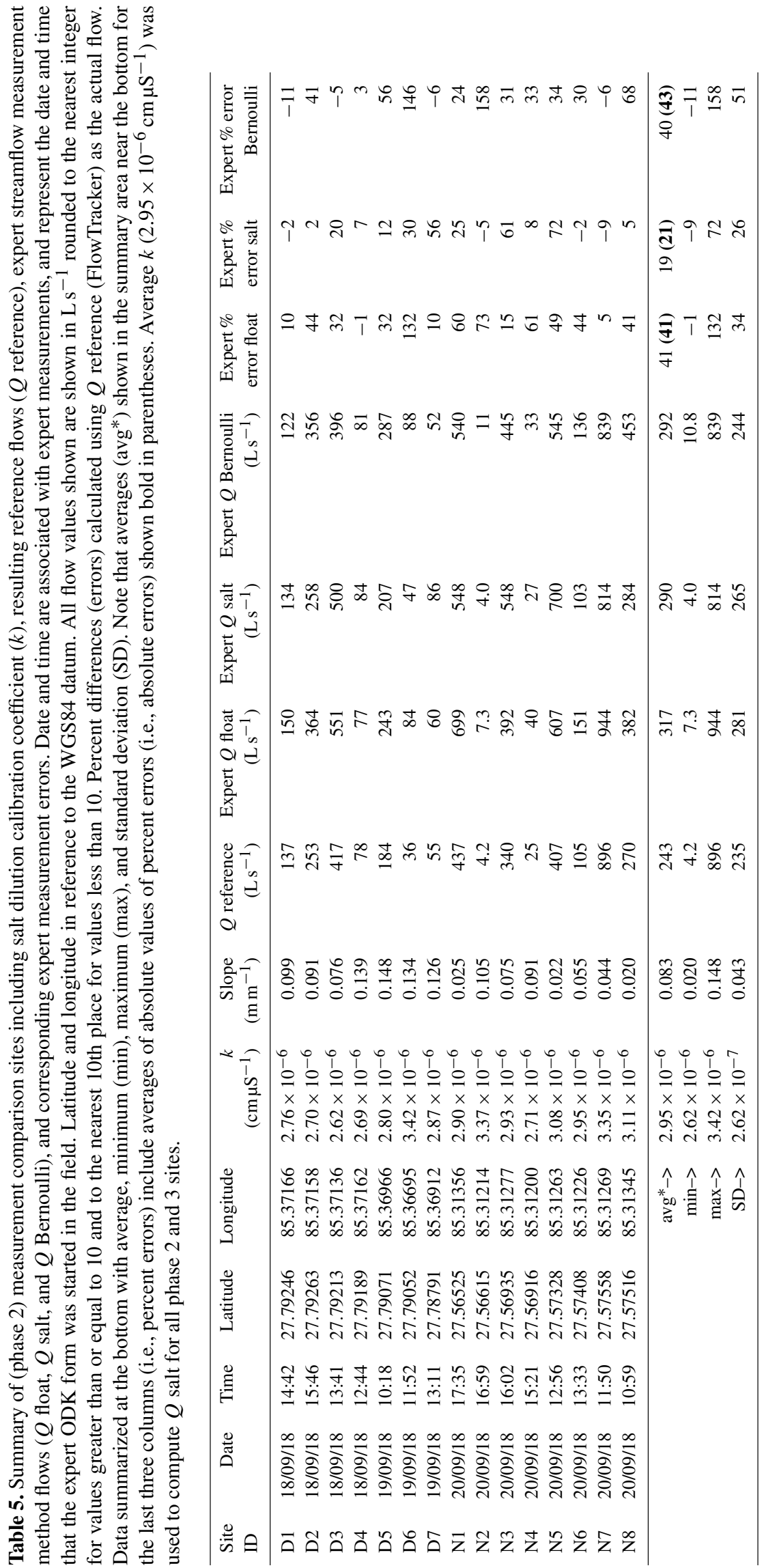


Bernoulli error medians and distributions were more variable in the Dhobi watershed than the Nakkhu watershed.

Overall, citizen scientists ranked the float method most favorably (43.2\% of rank 1 selections; average of blue bars) compared to Bernoulli and salt dilution methods, at $30.3 \%$ and $26.5 \%$, respectively (Fig. 5). In contrast, citizen scientists ranked the salt dilution method least favorably (64.0\% of rank 3 selections; average of tan bars) compared to Bernoulli and float methods, at $18.6 \%$ and $17.4 \%$, respectively. Most citizen scientists $(72.7 \%)$ thought the float method required the least amount of training (Q1), followed by the Bernoulli and salt dilution methods. Citizen scientists thought the Bernoulli method required the smallest investment in equipment $(45.5 \%$; Q2), the fewest number of citizen scientists $(54.5 \%$; 3$)$, and the least amount of data recording (42.4\%; Q4). Additionally, citizen scientists found the float method to be the least complex $(48.5 \%$; Q5), most enjoyable (60.6\%; Q6), and safest (42.4\%; Q7). Finally, most citizen scientists $(75.8 \%)$ thought the salt dilution method was most accurate (Q8), followed by the float and Bernoulli methods. The complete results from the survey are included in the Supplement.

\subsection{Citizen scientist application results (phase 3)}

Observed flows from the CS Flow campaign ( $n=131$ premonsoon; $n=133$ post-monsoon) were distributed among the 10 perennial headwater catchments of the Kathmandu Valley and ranged from 0.4 to $425 \mathrm{~L} \mathrm{~s}^{-1}$ and from 1.1 to $1804 \mathrm{~L} \mathrm{~s}^{-1}$ in the pre- and post-monsoon, respectively (Fig. 6a, b). The three locations in the Kathmandu Valley where the Nepal Department of Hydrology and Meteorology measures either water levels or flows (gauges) are included on Fig. 6a, b to illustrate the difference in spatial resolutions between the two datasets. Note that only one of the three DHM gauging stations is in a headwater catchment (i.e., Bagmati). Histograms of flow (Fig. 6c, d) and EC (Fig. 6e, f) show the increase in flows and the expected decrease in EC from pre- to post-monsoon.

\section{Discussion}

Of the simple streamflow measurement methods evaluated in this paper, salt dilution provides the most accurate streamflow measurements for both experts and citizen scientists alike. In both phase 1 and 2, the salt dilution method resulted in the lowest absolute errors and biases (Table 6) compared to the float and Bernoulli methods.

\subsection{Initial evaluation discussion (phase 1)}

Our first research question was the following: which simple streamflow measurement method provides the most accurate results when performed by "experts"? Based on phase 1 expert measurements, we found that salt dilution had the lowest absolute error (i.e., $15 \%$ ), compared to the float and Bernoulli methods (i.e., $23 \%$ and $37 \%$, respectively; Table 4).

The largest salt dilution errors occurred for reference flows of $21 \mathrm{~L} \mathrm{~s}^{-1}$ or less, while float and Bernoulli errors appeared to be more evenly distributed through the range of observed flows. Because salt dilution measurements of low flows require less salt and water, it is possible that larger relative measurement errors caused while measuring these small quantities led to larger overall measurement errors. However, this is not substantiated in phase 2 results, so additional research is required in this area.

Our experience in the field was that float velocity measurements in slow-moving and shallow areas were difficult to perform. The combination of turbulence and boundary layer impacts from the streambed and the overlying air mass often made floating objects on the surface travel in nonlinear paths, adding uncertainty to distance and time measurements. In the literature, challenges with applying the float method in shallow depths are supported by USBR (2001) and Escurra (2004), who showed that uncertainty in surface velocity coefficients (i.e., the ratio of surface velocity to actual mean velocity of the underlying water column; $\mathrm{C}$ from Eq. 1) increased as depth decreased, especially below $0.3 \mathrm{~m}$. The impacts of shallow depths on the surface velocity coefficient $C$ should be the focus of additional research.

A primary challenge we experienced with Bernoulli measurements was keeping the flat plate at the same vertical location while rotating the plate from parallel to perpendicular to the flow direction (Sect. 2.2.3). This was usually due to the bottom of the flat plate being set on a streambed consisting of sands and gravels that could be easily disturbed during rotation. Slow water velocities, and correspondingly small changes in Bernoulli depths (Eq. 4), further compounded this issue. Adding a circular metal plate to the bottom of the flat plate used for Bernoulli depth measurements could help minimize these uncertainties.

Based on the 10 measured $k$ values in phase 1 , using an average $k$ for all salt dilution measurements caused the largest percent difference in salt dilution flow (Eq. 2) for site 7 (8.6\% increase in flow) followed by site 19 (7.6\% decrease in flow). For phase 2, using average $k$ values for all salt dilution measurements caused the largest percent difference in salt dilution flow (Eq. 2) for site D6 (13.7\% decrease in flow) followed by site D3 (12.6\% increase in flow). Because observed absolute error distributions from phase 1, and especially phase 2 , are larger than errors introduced by using average $k$ values (sometimes by more than an order of magnitude), we do not think our overall findings are negatively impacted by using average $k$ values. However, because of the sensitivity of salt dilution measurements to $k$ (Eq. 2), future work should focus on improving understanding of the variables affecting $k$. Specifically, spatial and temporal variability in $k$ due to changes in stream water chemistry should be investigated prior to applying the salt dilution methodol- 
Table 6. Summary of average absolute errors, average biases, and error standard deviations (SD error) for phase 1 and 2 measurements. All values are shown as percentages rounded to the nearest integer.

\begin{tabular}{|c|c|c|c|c|c|}
\hline Phase & Performed by & Metric & $\begin{array}{r}\text { Float } \\
\text { method }\end{array}$ & $\begin{array}{r}\text { Salt dilution } \\
\text { method }\end{array}$ & $\begin{array}{r}\text { Bernoulli } \\
\text { method }\end{array}$ \\
\hline \multirow[t]{3}{*}{1} & Authors & Average absolute errors (\%) & 23 & 15 & 37 \\
\hline & & Average biases (avg. error, \%) & 8 & 6 & 26 \\
\hline & & $\mathrm{SD}$ error $(\%)$ & 29 & 19 & 62 \\
\hline \multirow[t]{3}{*}{2} & Expert (authors) & Average absolute errors (\%) & 41 & 21 & 43 \\
\hline & & Average biases (avg. error, \%) & 41 & 19 & 40 \\
\hline & & $\mathrm{SD}$ error $(\%)$ & 34 & 26 & 51 \\
\hline \multirow[t]{3}{*}{2} & CS Flow groups & Average absolute errors $(\%)$ & 63 & 28 & 131 \\
\hline & & Average biases (avg. error, \%) & 52 & 7 & 127 \\
\hline & & SD error $(\%)$ & 82 & 36 & 225 \\
\hline
\end{tabular}

ogy described in this paper in other areas. For citizen science projects in other areas, we recommend that locally appropriate average $k$ values be determined from measurements at multiple sites to understand spatial variability. Additional $k$ measurements should also be repeated in different seasons to understand temporal variability.

\subsection{Citizen scientist evaluation discussion (phase 2)}

Our second research question was the following: which simple streamflow measurement method provides the most accurate results when performed by citizen scientists? Based on phase 2 citizen scientist measurements, we found that salt dilution had the lowest absolute error (i.e., $28 \%$ ) compared to the float and Bernoulli methods (i.e., $63 \%$ and $131 \%$; Fig. 4).

While absolute error distributions for citizen scientists followed the same trend to that of expert measurements, the relative increases in errors for float $(41 \%$ to $63 \%$; increase of $54 \%$ ) and Bernoulli (43\% to $131 \%$; increase of $205 \%$ ) methods were larger than that of salt dilution ( $21 \%$ to $28 \%$; increase of $33 \%$ ). This could be due in part to the fact that salt dilution measurement errors may be less sensitive to a lack of field data collection experience. For example, as long as turbulent mixing conditions are present (which can be controlled by proper site selection during the experimental design phase), citizen scientists can primarily introduce errors into salt dilution measurements by (1) making mistakes in measurement or recording of amounts of salt and/or water used to prepare tracer solutions, (2) not thoroughly mixing tracer solution until all salt is dissolved, (3) not providing enough distance between salt injection and EC measurement points (recommended as 25 stream widths by Day, 1977; Butterworth et al., 2000; Moore, 2005), or (4) recording videos of EC changes that are difficult to read. Each of these sources of error can be minimized by implementing relatively easy to follow protocols such as "be sure to mix the salt and water until you cannot see the salt any longer."
In contrast, while performing float and Bernoulli measurements, citizen scientists need to accurately characterize (1) average stream depth, (2) stream width, and (3) average water velocity. Characterizing average depth and velocity requires several individual measurements, each coming with the chance of introducing measurement errors. Additionally, selecting the number of subsections required and the representative locations for each of these subsections can be difficult, even for people with extensive streamflow data collection experience. These factors may help explain the wider error distributions observed in float and Bernoulli methods compared to salt dilution (Fig. 4). Additional training might also help to close the observed differences between salt dilution error distributions and that of float and Bernoulli methods.

Our third research question was the following: what are citizen scientists' perceptions of the required training, cost, accuracy, etc. of the evaluated simple streamflow measurement methods? Based on a survey of 33 citizen scientists, we found that volunteers ranked the float method most favorably (43.2\% of rank 1 selections) compared to Bernoulli and salt dilution methods, at $30.3 \%$ and $26.5 \%$, respectively (Fig. 5).

Regarding question number four from the perception survey (i.e., data-recording requirements), it is interesting to note that salt dilution received the least favorable ranking, meaning that citizen scientists perceived salt dilution to require the greatest amount of data. Our perception was that salt dilution, in terms of individual pieces of information, requires the least amount of data recording. This ranking may be explained by either (1) the amount of metadata collected about salt dilution measurements (i.e., GPS and photos of salt injection and EC measurement locations; see Sect. 2.4.2 and the Supplement for details) or by (2) citizen scientists' perception of using a digital EC meter and smartphone video for recording lots of individual pieces of data, when in some ways a video can be thought of as a single observation. Whereas results from float and Bernoulli method measurements are available immediately in the ODK form, the post- 
processing requirements of EC breakthrough curve data to solve for salt dilution flow may also lead to the perception that salt dilution measurements have higher data-recording requirements.

Citizen scientists ranked the float method as the safest, followed by salt dilution, and finally Bernoulli. We found this result to be somewhat counter intuitive, because salt dilution is the only method that can be performed without entering the stream, whereas for float and Bernoulli measurements the entire stream must be waded across to get depth and velocity data. Because the perception survey was performed after phase 2 evaluations where all three methods were performed consecutively, it may not have been obvious to citizen scientists that salt doses could be obtained without entering the stream from visual estimates of channel width, depth, and water velocity.

In terms of perceived measurement accuracy (question 8), $75.8 \%$ of citizen scientists ranked salt dilution as the most accurate method. This ranking was performed before any quantitative results were reviewed. Our experience is that reading a value from a digital meter often gives an unfounded sense of measurement accuracy. The salt dilution method's perceived accuracy may be due to it being the only method that directly involves a digital measurement device (i.e., EC meter).

Expert absolute errors for float, salt dilution, and Bernoulli increased from $23 \%, 15 \%$, and $37 \%$ in phase 1 to $41 \%$, $21 \%$, and $43 \%$ in phase 2 . For the float method, this increase in error may be partially explained by the overall increase in flows from pre-monsoon (phase 1; average reference flow of $92 \mathrm{~L} \mathrm{~s}^{-1}$ ) to post-monsoon (phase 2; average reference flow of $243 \mathrm{~L} \mathrm{~s}^{-1}$ ). Our experience was that increased flow and velocity in high-gradient headwater streams made it more difficult to perform float measurements. This was mostly due to an increase in turbulence resulting in more nonlinear flow lines and increased relative measurement uncertainty for shorter float times (assuming distances were held constant). For the Bernoulli method, however, our hypothesis was that increased velocities would on average reduce measurement errors, because of decreased relative measurement uncertainty for larger Bernoulli depth changes. This hypothesis however was not supported by the data. The challenge of pulsing flows which require citizen scientists to visually average short-period (i.e., seconds or less) water level fluctuations may also counteract the otherwise larger Bernoulli depth changes. We do not have any explanations for the overall increase in salt dilution method absolute error from $15 \%$ to $21 \%$ from phase 1 to phase 2 . Unlike the phase 1 results, we also do not see a concentration of larger errors at the lower reference flows in phase 2 .

\subsection{Citizen scientist application discussion (phase 3)}

To proceed with phase 3, we had to select a preferred simple streamflow measurement method. Based on the results from phase 1 and 2, the salt dilution method had the lowest absolute errors, biases, and error standard deviations for both experts and citizen scientists. Therefore, from an accuracy perspective, salt dilution was the preferred approach. However, the results of our perception survey showed that citizen scientists thought the float method was most enjoyable (Q6) and required the least amount of training (Q1). Another important consideration was that salt dilution is the only method that does not require citizen scientists to enter and cross the stream and therefore can be safely performed over a broader range of flow conditions. While the enjoyment of measurements is an important motivational factor for citizen scientists, we concluded that accuracy and safety were ultimately more important. Considering all these factors, we selected the salt dilution method as the preferred approach.

Finally, our fourth research question was the following: can citizen scientists apply the selected streamflow measurement method at a larger scale? Based on measurements from pre- $(n=131)$ and post-monsoon $(n=133)$ in the Kathmandu Valley, citizen scientists can apply salt dilution streamflow measurements at a larger scale; however, challenges of recruiting, training, and motivating citizen scientists, along with data management issues, require further investigation.

The CS Flow campaigns provided us with a unique opportunity to evaluate the preferred salt dilution streamflow measurement method with more people at more sites. In addition to the valuable streamflow data that will help us characterize the water supply situation in the Kathmandu Valley with greater precision for pre- and post-monsoon periods, we also learned several practical lessons about how to scale citizen-science-based streamflow measurements. For example, our experience was that digitizing breakthrough curves from ODK-captured EC videos took roughly 15 to $30 \mathrm{~min}$ per site, depending on video length and quality. Additionally, managing EC change videos can be a significant challenge if videos are recorded at a smartphones' native resolution. In some cases, each minute of high-definition video can be nearly $100 \mathrm{MB}$. Uploading such large files, and subsequently storing and accessing them, can be challenging and costly. These difficulties can be solved by improved training and protocols regarding video collection settings and, when necessary, video compression.

\section{Conclusions and future work}

Compared to the float and Bernoulli methods, the salt dilution method consistently yielded the most accurate streamflow measurement results for authors and citizen scientists alike. Given ongoing global declines in the amount of streamflow data being collected by traditional entities, salt dilution measurements performed by young researchers and citizen scientists could play an important role in closing this data 
gap. While globally applicable, this is especially true for headwater catchments in developing regions.

With regards to young researchers (i.e., science- and engineering-minded students from primary through graduate school ages), performing salt dilution streamflow measurements has the benefits of (1) filling data gaps and (2) improving the quality and applicability of students' educational experience. We suggest that science and engineering educators should make smartphone-based data collection activities a core component of their curricula. Moreover, these data should be collected together with globally active partners to ensure standardization and open access to data.

As a step in this direction, SmartPhones4Water and S4WNepal, in partnership with local educators, are working towards broader applications of salt dilution streamflow measurements in Nepal and beyond. Importantly, variability in the calibration coefficient $(k)$ should be evaluated over larger ranges of time, geology, and water quality. Another practical challenge requiring specific attention is the transfer, management, and digitization of breakthrough curve video files. The information content of additional headwater streamflow data should be explored, especially regarding the trade-offs between observation density and accuracy. Efforts should focus on how to effectively recruit and motivate young researchers and citizen scientists to participate in citizen science streamflow measurements. Lastly, emphasis should be placed on exploring these and other citizen-science-related questions in the relatively unexplored Asian context.

Data availability. The data used in this paper are provided in the Supplement.

Supplement. The supplement related to this article is available online at: https://doi.org/10.5194/hess-23-1045-2019-supplement.

Author contributions. JCD had the initial idea for this investigation and designed the experiments in collaboration with MMR, WDvO, and NvdG. Field work was performed by JCD, AP, ND, WDvO, and RP. JCD prepared the manuscript with valuable contributions from all co-authors.

Competing interests. The authors declare that they have no conflict of interest.

Acknowledgements. This work was supported by the Swedish International Development Agency under grant number 2016-05801 and by SmartPhones4Water (S4W). We appreciate the dedicated efforts of Annette van Loosen, Bhumika Thapa, Sunil Duwal, citizen scientists from Khwopa College of Engineering, Anurag Gyawali, Anu Grace Rai, Sanam Tamang, Eliyah Moktan, Surabhi Upadhyay, Amber Bahadur Thapa, Pratik Shrestha, Kristi Davids, and the rest of the S4W-Nepal team of young researchers. Thanks to Kate Happee, Niek Moesker, Nick N. Overkamp, and Rick van Bentem from the 2018 multidisciplinary group of master's degree students from Delft University of Technology for their fresh energy during post-monsoon field work. We would also like to thank Ram Devi Tachamo Shah, Deep Narayan Shah, Narendra Man Shakya, and Steve Lyon for their supervision and support of this work. A special thanks to SonTek for their donation of a FlowTracker acoustic Doppler velocimeter that was used for the reference flow measurements discussed in this paper and many more to come. Finally, thanks to two anonymous reviewers for their useful comments.

Edited by: Laurent Pfister

Reviewed by: two anonymous referees

\section{References}

Almeida, A. S. and de Souza, V. C. B.: An alternative method for measuring velocities in open-channel flows: performance evaluation of a Pitot tube compared to an acoustic meter, Brazilian J. Water Resour., 22, https://doi.org/10.1590/23180331.011716099, 2017.

Anokwa, Y., Hartung, C., and Brunette, W.: Open Source Data Collection in the Developing World, IEEE Comp. Soc., 42, 97-99, https://doi.org/10.1109/MC.2009.328, 2009.

Assumpção, T. H., Popescu, I., Jonoski, A., and Solomatine, D. P.: Citizen observations contributing to flood modelling: opportunities and challenges, Hydrol. Earth Syst. Sci., 22, 1473-1489, https://doi.org/10.5194/hess-22-1473-2018, 2018.

British Standards Institute: Method of Measurement of Liquid Flow in Open Channels, British Standards 3680, Part 3, 1964.

Burt, T. P. and McDonnell, J. J.: Whither field hydrology? the need for discovery science and outrageous hydrological hypotheses, Water Resour. Res., 51, 5919-5928, https://doi.org/10.1002/2014WR016839, 2015.

Butterworth, J. A., Hewitt, E. J., and McCartney, M. P.: Discharge measurement using portable dilution gauging flowmeters, J. Chart. Inst. Water Environ. Manag., 14, 436-441, https://doi.org/10.1111/j.1747-6593.2000.tb00291.x, 2000.

Buytaert, W., Zulkafli, Z., Grainger, S., Acosta, L., Alemie, T. C., Bastiaensen, J., De BiÂvre, B., Bhusal, J., Clark, J., Dewulf, A., Foggin, M., Hannah, D. M., Hergarten, C., Isaeva, A., Karpouzoglou, T., Pandeya, B., Paudel, D., Sharma, K., Steenhuis, T., Tilahun, S., Van Hecken, G., and Zhumanova, M.: Citizen science in hydrology and water resources: opportunities for knowledge generation, ecosystem service management, and sustainable development, Front. Earth Sci., 2, 1-21, https://doi.org/10.3389/feart.2014.00026, 2014.

Carufel, L. H.: Construction and Use of a Velocity Head Rod for Measuring Stream Velocity and Flow, BLM/AK Technical Report 5, 1-10, 1980.

Church, M. and Kellerhals, R.: Stream gauging techniques for remote areas using portable equipment, Can. Inl. Waters Branch, Dep. Energy, Mines, Resour., Technical Bulletin 25, 1-89, 1970.

Davids, J. C., van de Giesen, N., and Rutten, M.: Continuity vs. the Crowd - Tradeoffs Between Continuous and Intermittent Citizen 
Hydrology Streamflow Observations, Environ. Manage., 60, 1229, https://doi.org/10.1007/s00267-017-0872-x, 2017.

Davids, J. C., Rutten, M. M., Shah, R. D. T., Shah, D. N., Devkota, N., Izeboud, P., Pandey, A., and van de Giesen, N.: Quantifying the connections - linkages between land-use and water in the Kathmandu Valley, Nepal, Environ. Monit. Assess., 190, https://doi.org/10.1007/s10661-018-6687-2, 2018.

Day, T. J.: On the precision of salt dilution gauging, J. Hydrol., 31, 293-306, https://doi.org/10.1016/0022-1694(76)90130-X, 1976.

Day, T. J.: Observed mixing lengths in mountain streams, J. Hydrol., 35, 125-136, https://doi.org/10.1016/0022-1694(77)90081-6, 1977.

Dickinson, J. L., Zuckerberg, B., and Bonter, D. N.: Citizen Science as an Ecological Research Tool: Challenges and Benefits, Annu. Rev. Ecol. Evol. Syst., 41, 149-172, https://doi.org/10.1146/annurev-ecolsys-102209-144636, 2010.

Dramais, G., Le Coz, J., Camenen, B., and Hauet, A.: Advantages of a mobile LSPIV method for measuring flood discharges and improving stage-discharge curves, J. Hydro-Environ. Res., 5, 301312, https://doi.org/10.1016/j.jher.2010.12.005, 2011.

Durand, M., Neal, J., Rodríguez, E., Andreadis, K. M., Smith, L. C., and Yoon, Y.: Estimating reach-averaged discharge for the River Severn from measurements of river water surface elevation and slope, J. Hydrol., 511, 92-104, https://doi.org/10.1016/j.jhydrol.2013.12.050, 2014.

Escurra, J.: Field Calibration of the Float Method in Open Channels, M.S., Utah State University, Logan, Utah, USA, 83 pp., 2004.

Etter, S., Strobl, B., Seibert, J., and van Meerveld, H. J. I.: Value of uncertain streamflow observations for hydrological modelling, Hydrol. Earth Syst. Sci., 22, 5243-5257, https://doi.org/10.5194/hess-22-5243-2018, 2018.

Feki, H., Slimani, M., and Cudennec, C.: Geostatistically based optimization of a rainfall monitoring network extension: case of the climatically heterogeneous Tunisia, Hydrol. Res., 48, 514-541, https://doi.org/10.1016/0720-048X(90)90119-V, 2017.

Fienen, M. N. and Lowry, C. S.: Social.Water-A crowdsourcing tool for environmental data acquisition, Comput. Geosci., 49, 164 169, https://doi.org/10.1016/j.cageo.2012.06.015, 2012.

Fleming, B. and Henkel, D.: Community-based ecological monitoring: A rapid appraisal approach, J. Am. Plan. Assoc., 67, 456465, https://doi.org/10.1080/01944360108976252, 2001.

Fonstad, M. A., Reichling, J. P., and Van de Grift, J. W.: The Transparent Velocity-Head Rod for Inexpensive and Accurate Measurement of Stream Velocities, J. Geosci. Educ., 53, 44-52, https://doi.org/10.5408/1089-9995-53.1.44, 2005.

Hannah, D. M., Demuth, S., van Lanen, H. A. J., Looser, U., Prudhomme, C., Rees, G., Stahl, K., and Tallaksen, L. M.: Large-scale river flow archives: Importance, current status and future needs, Hydrol. Process., 25, 1191-1200, https://doi.org/10.1002/hyp.7794, 2011.

Harmel, R. D., Cooper, R. J., Slade, R. M., Haney, R. L., and Arnold, J. G.: Cumulative Uncertainty in Measured Streamflow and Water Quality Data for Small Watersheds, Trans. ASABE, 49, 689-702, https://doi.org/10.13031/2013.20488, 2006.

Harrelson, C. C., Rawlins, C. L., and Potyondy, J. P.: Stream Channel Reference Sites: An Illustrated Guide to Field Technique, U.S. Department of Agriculture, Forest Service, Rocky Mountain Forest and Range Experiment Station, Fort Collins, CO, USA, 61 pp., 1994.
Herschy, R. W.: Streamflow measurement, 3rd Edition, CRC Press, Abingdon, England, 510 pp., 2009.

Kirchner, J. W.: Getting the right answers for the right reasons: Linking measurements, analyses, and models to advance the science of hydrology, Water Resour. Res., 42, 1-5, https://doi.org/10.1029/2005WR004362, 2006.

Kruger, L. E. and Shannon, M. A.: Getting to know ourselves and our places through participation in civic social assessment, Soc. Nat. Resour., 13, 461-478, https://doi.org/10.1080/089419200403866, 2000.

Kundzewicz, Z. W.: Water resources for sustainable development, Hydrol. Sci. J., 42, 467-480, https://doi.org/10.1080/02626669709492047, 1997.

Le Boursicaud, R., Pénard, L., Hauet, A., Thollet, F., and Le Coz, J.: Gauging extreme floods on YouTube: Application of LSPIV to home movies for the post-event determination of stream discharges, Hydrol. Process., 30, 90-105, https://doi.org/10.1002/hyp.10532, 2016.

Le Coz, J., Hauet, A., Pierrefeu, G., Dramais, G., and Camenen, B.: Performance of image-based velocimetry (LSPIV) applied to flash-flood discharge measurements in Mediterranean rivers, J. Hydrol., 394, 42-52, https://doi.org/10.1016/j.jhydrol.2010.05.049, 2010.

Le Coz, J., Patalano, A., Collins, D., Guillén, N. F., García, C. M., Smart, G. M., Bind, J., Chiaverini, A., Le Boursicaud, R., Dramais, G., and Braud, I.: Crowdsourced data for flood hydrology: Feedback from recent citizen science projects in Argentina, France and New Zealand, J. Hydrol., 541, 766-777, https://doi.org/10.1016/j.jhydrol.2016.07.036, 2016.

Lukyanenko, R., Parsons, J., and Wiersma, Y. F.: Emerging problems of data quality in citizen science, Conserv. Biol., 30, 447449, https://doi.org/10.1111/cobi.12706, 2016.

Lüthi, B., Philippe, T., and Peña-Haro, S.: Mobile device app for small open-channel flow measurement, in: 7th Intl. Congress in Environ. Model. Softw., vol. 1, 15-19, 2014.

Mazzoleni, M., Verlaan, M., Alfonso, L., Monego, M., Norbiato, D., Ferri, M., and Solomatine, D. P.: Can assimilation of crowdsourced data in hydrological modelling improve flood prediction?, Hydrol. Earth Syst. Sci., 21, 839-861, https://doi.org/10.5194/hess-21-839-2017, 2017.

McCulloch, J. S. G.: Book Review: Streamflow measurement, Reginald W. Herschy, 1995, E. and FN Spon, an imprint of Chapman and Hall, London, 524 pp., ISBN 0-419-19490-8, J. Hydrol., 176, 285-286, 1996.

Mishra, A. K. and Coulibaly, P.: Developments in Hydrometric Network Design?: a Review, Rev. Geophys., 2007, 1-24, https://doi.org/10.1029/2007RG000243, 2009.

Moore, R. D.: Introduction to salt dilution gauging for streamflow measurement: Part I, Streamline Watershed Manag. Bull., 7, 20 23, 2004a.

Moore, R. D.: Introduction to Salt Streamflow Measurement Part II: Constant-rate Injection, Streamline Watershed Manag. Bull., 8, 11-15, 2004b.

Moore, R. D.: Introduction to Salt Dilution Gauging for Streamflow Measurement Part III: Slug Injection Using Salt Solution, Streamline Watershed Manag. Bull., 8, 1-6, 2005.

Mulligan, M.: WaterWorld: a self-parameterising, physically based model for application in data-poor but problem- 
rich environments globally, Hydrol. Res., 44, 748-769, https://doi.org/10.2166/nh.2012.217, 2013.

Muste, M., Fujita, I., and Hauet, A.: Large-scale particle image velocimetry for measurements in riverine environments, Water Resour. Res., 46, 1-14, https://doi.org/10.1029/2008WR006950, 2008.

Nayava, J. L.: Heavy Monsoon Rainfall in Nepal, Weather, 29, 443 450, https://doi.org/10.1002/j.1477-8696.1974.tb03299.x, 1974.

O'Grady, M. J., Muldoon, C., Carr, D., Wan, J., Kroon, B., and O'Hare, G. M. P.: Intelligent Sensing for Citizen Science, Mob. Networks Appl., 21, 375-385, https://doi.org/10.1007/s11036016-0682-z, 2016.

Pearson, C. P.: Changes to New Zealand's national hydrometric network in the 1990s, J. Hydrol. New Zeal., 37, 1-17, 1998.

Peña-Haro, S., Lüthi, B., Carrel, M., and Philippe, T.: DischargeApp?: A smart-phone App for measuring river discharge, EGU Gen. Assem., Vienna, Austria, 7-12 April 2018, Vol. 20, EGU2018-1757, 2018.

Rantz, S. E.: Measurement and computation of stream flow. Volume 1: Measurement of stage and discharge; Volume 2: Computation of discharge, US Geol. Surv. Water Supply Pap. 2175, US Geol. Surv., Washington, D.C., USA, 631 pp., https://doi.org/10.1029/WR017i001p00131, 1982.

Sanz, F. S., Holocher-Ertl, T., Kieslinger, B., García, F. S., and Silva, C. G.: White Paper on Citizen Science in Europe, available at: http://www.socientize.eu/sites/default/files/white-paper_ 0.pdf (last access: 27 June 2018), 2014.

SonTek: Handheld ADV ${ }^{\circledR}$ s Technical Manual Firmware Version 3.3 Software Version 2.20, SonTek YSI Incorporated, San Diego, California, 2009.

SRTM: Shuttle Radar Topography Mission, available at: https:// earthexplorer.usgs.gov/ (last access: 14 September 2016), 2000.

Tauro, F., Selker, J., Van De Giesen, N., Abrate, T., Uijlenhoet, R., Porfiri, M., Manfreda, S., Caylor, K., Moramarco, T., Benveniste, J., Ciraolo, G., Estes, L., Domeneghetti, A., Perks, M. T., Corbari, C., Rabiei, E., Ravazzani, G., Bogena, H., Harfouche, A., Broccai, L., Maltese, A., Wickert, A., Tarpanelli, A., Good, S., Lopez Alcala, J. M., Petroselli, A., Cudennec, C., Blume, T., Hut, R., and Grimaldia, S.: Measurements and observations in the XXI century (MOXXI): Innovation and multi-disciplinarity to sense the hydrological cycle, Hydrol. Sci. J., 63, 169-196, https://doi.org/10.1080/02626667.2017.1420191, 2018.
Tetzlaff, D., Soulsby, C., Carey, S. K., Mcnamara, J. P., and Laudon, H.: The essential value of long-term experimental data for hydrology and water management, Water Resour. Res., 53, 25982604, https://doi.org/10.1002/2017WR020838, 2017.

Tourian, M. J., Sneeuw, N., and Bardossy, A.: A quantile function approach to discharge estimation from satellite altimetry (ENVISAT), Water Resour. Res., 49, 4174-4186, https://doi.org/10.1002/wrcr.20348, 2013.

Turner, D. S. and Richter, H. E.: Wet/Dry Mapping: Using Citizen Scientists to Monitor the Extent of Perennial Surface Flow in Dryland Regions, Environ. Manage., 47, 497-505, https://doi.org/10.1007/s00267-010-9607-y, 2011.

USBR (United States Bureau of Reclamation): Water Measurement Manual, 3rd Edition Revised Reprinted, US Government Printing Office, Washington, D.C. available at: https://www.usbr.gov/ tsc/techreferences/mands/wmm/WMM_3rd_2001.pdf (last access: 13 September 2018), 2001.

van de Giesen, N., Hut, R., and Selker, J.: The Trans-African HydroMeteorological Observatory (TAHMO), Wiley Interdiscip. Rev. Water, 1, 341-348, https://doi.org/10.1002/wat2.1034, 2014.

van Meerveld, H. J. I., Vis, M. J. P., and Seibert, J.: Information content of stream level class data for hydrological model calibration, Hydrol. Earth Syst. Sci., 21, 4895-4905, https://doi.org/10.5194/hess-21-4895-2017, 2017.

WMO (World Meteorological Organization): Manual on Stream Gauging, Volume II - Computation of Discharge, No. 1044, 2010 . 